\title{
Representação de Léxicos Através de Autômatos Finitos
}

\author{
Marcelo Alexandre Couto de Jesus
}

Orientadora: Profa. Dra. Maria das Graças Volpe Nunes

Dissertação apresentada ao Instituto de Ciências Matemáticas e de Computação - ICMC-USP, como parte dos requisitos para obtenção do título de Mestre em Ciências - Área: Ciências de Computação e Matemática Computacional.

São Carlos

Novembro/1999 
Dedico esse trabalho à

minha filha, Lia. 
Agradeço a todos os meus amigos que me ajudaram durante esses anos, tanto no âmbito acadêmico como no pessoal.

Em especial à minha esposa Claudia, a quem conheci durante o mestrado, e que tem sido sempre uma ótima companheira em todos os momentos.

À minha orientadora Graça, por toda a ajuda e incentivo que sempre me deu, e também por ter que 'aturar' meu modo de trabalho.

À minha família, por sempre ter me proporcionado condições de estudar e de ter chegado até esse ponto.

À comunidade que desenvolve softwares de domínio público, como o Linux, o GNU C Compiler, malloc debuggers, e muitas outras ferramentas que permitiram que esse trabalho fosse desenvolvido e executado de forma eficiente.

À FAPESP, que proporcionou um suporte imprescindível ao projeto. 


\section{Índice Analítico}

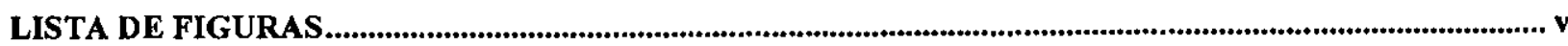

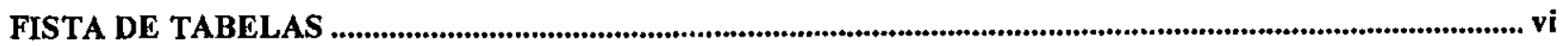

RESUMO.......................................................................................................................................................... vii

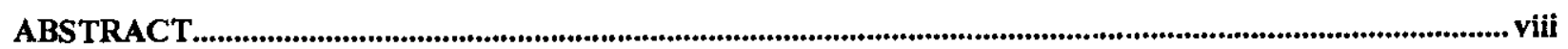

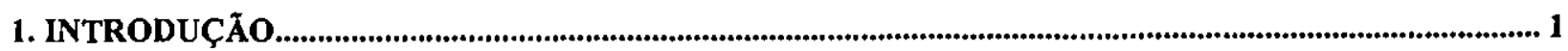

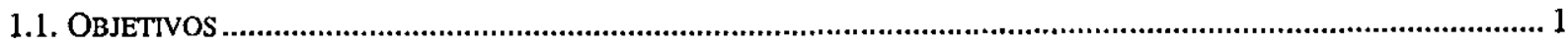

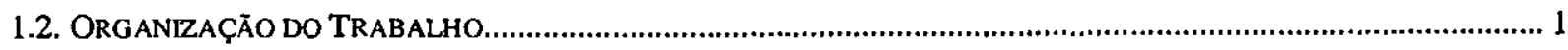

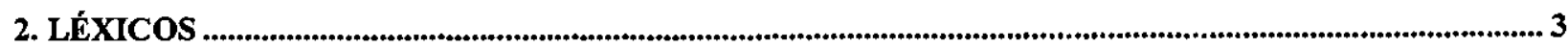

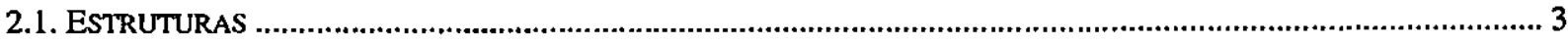

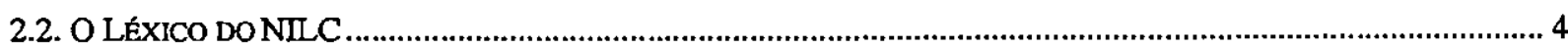

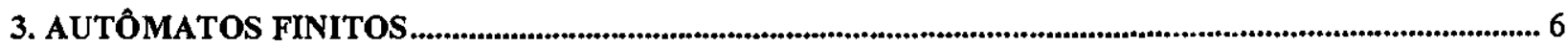

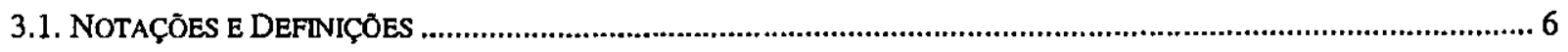

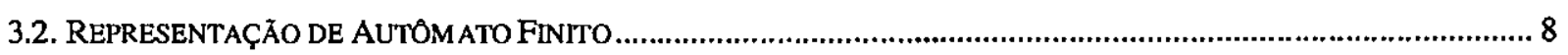

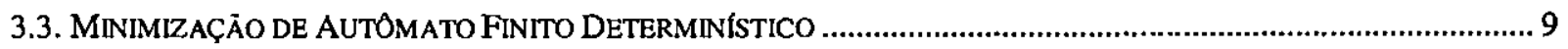

3.4. PACOTES PARA MANIPULAÇÃo DE AUTÔMATOS FINITOS ............................................................................. 11

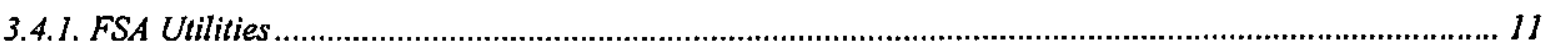

3.4.2. FIRE Lite

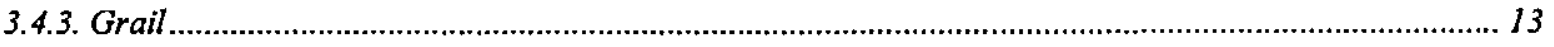

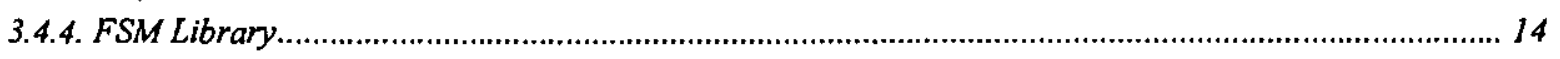

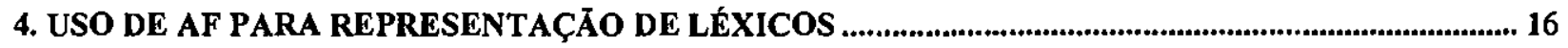

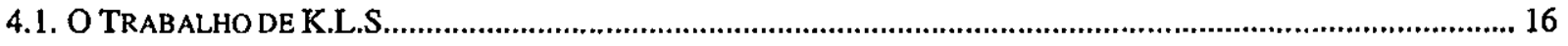

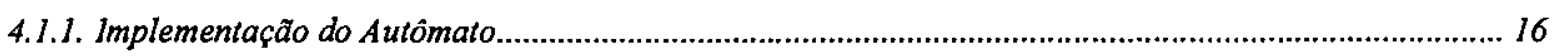

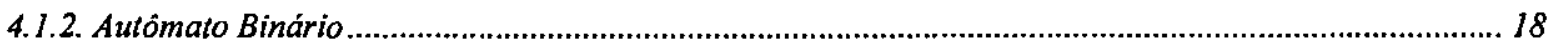

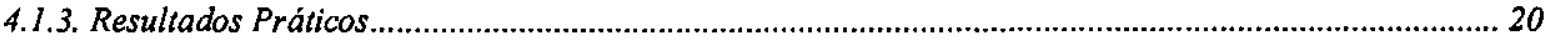

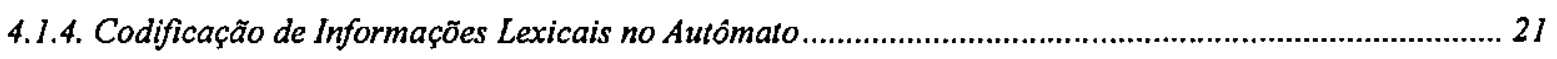

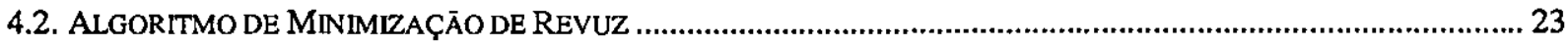

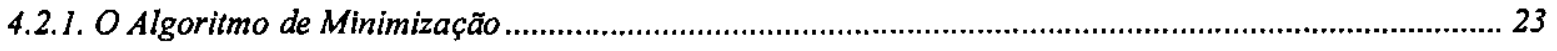

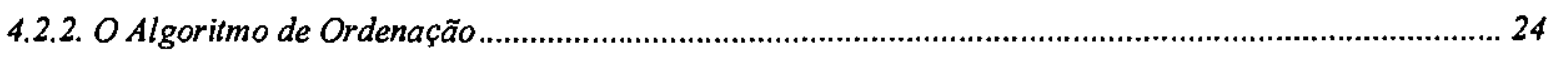

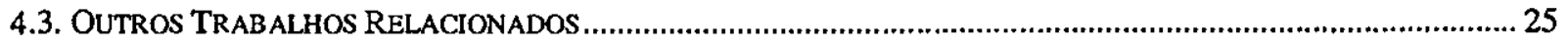

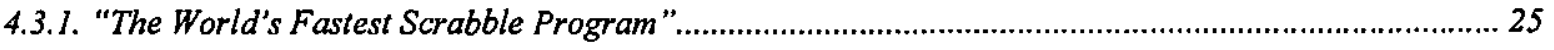

4.3.2. "Verifica" - Uma Ferramenta de Auxilio à Redação....................................................................... 25

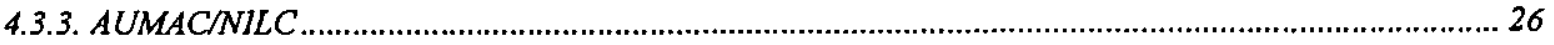

4.3.4. JNTEX 
5. UM SISTEMA DE REPRESENTAÇÃO DE GRANDES AF DETERMINÍSTICOS ACÍCLICOS ............. 32

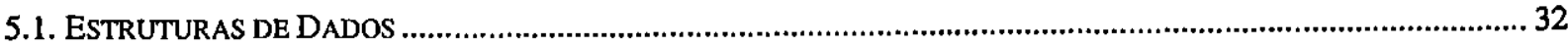

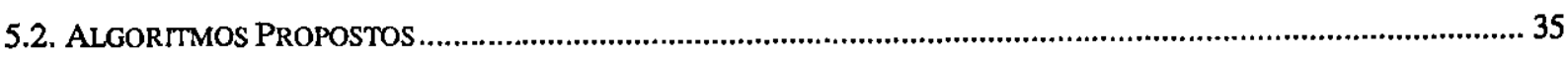

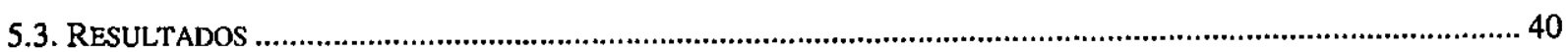

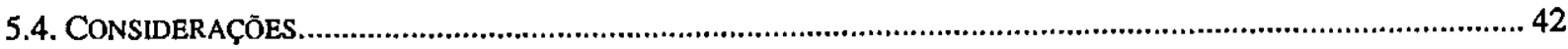

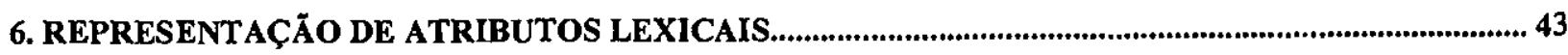

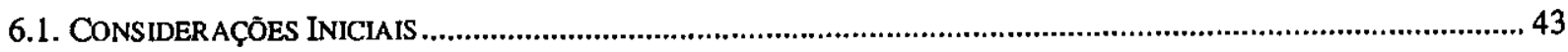

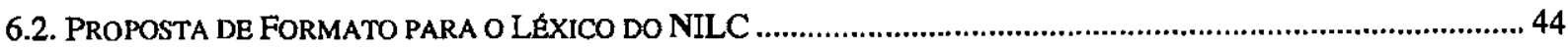

6.2.1. BNF do Formato Proposto de Léxico ......................................................................................... 46

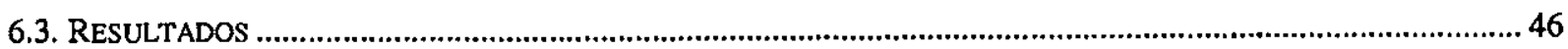

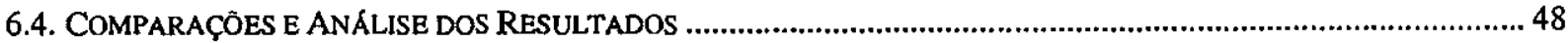

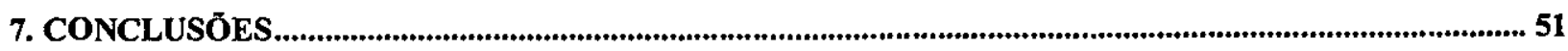

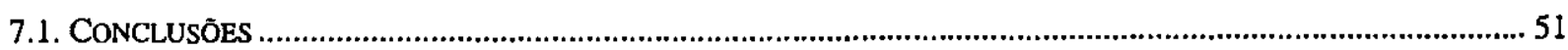

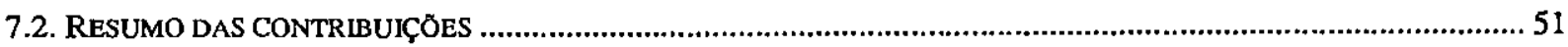

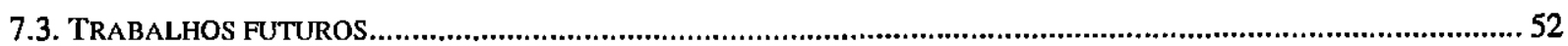

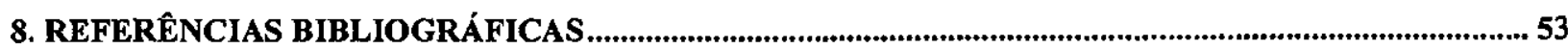

APÊNDICE A -- B.N.F. DO LÉXICO DO NILC 


\section{Lista de Figuras}

FIGURA I - EXEMPLO DE AUTOMATO FINITO DETERMINISTICO …....................................................................... 7

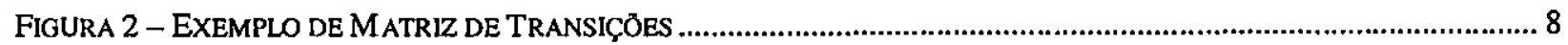

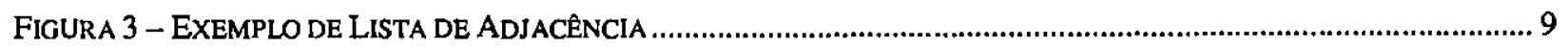

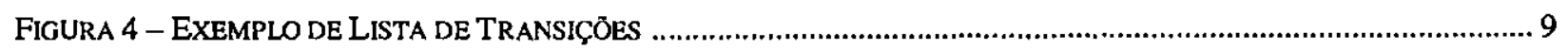

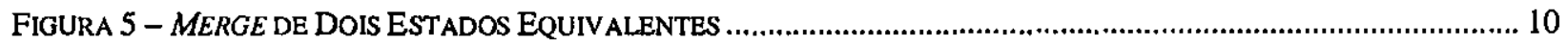

FIGURA 6 - AUTÓMATO PARA TODAS AS FORMAS DOS VERBOS REWORK, REPLAY, OVERWORK E OVERPLAY ................. 17

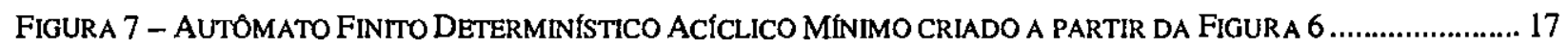

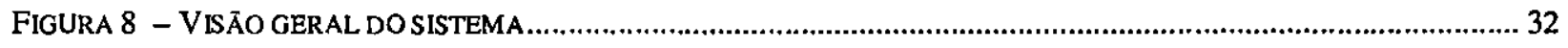

FIGURA 9 - PROCESSO DE INSERÇÃO DE UMA PALAVRA NO AUTÔMATO …….................................................... 36

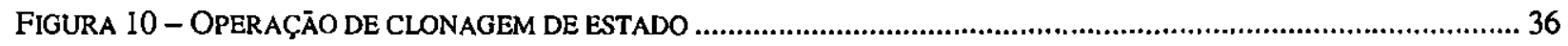

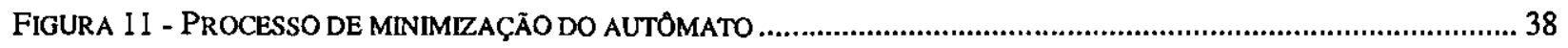

FIGURA 12 - PROCESSO DE CRIAÇÃO DA REPRESENTAÇAO FINAL DO AUTÓMATO .................................................... 39

FIGURA 13 - PROCESSO DE BUSCA DE UMA PALAVRA NA ESTRUTURA FINAL ....................................................... 40

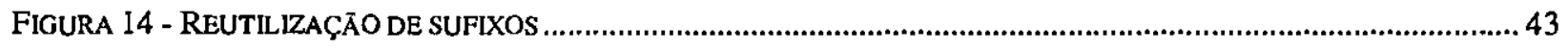

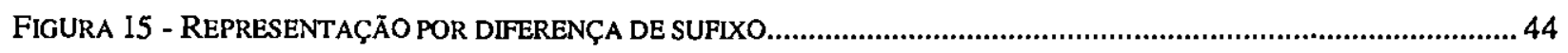

FIGURA I6 - RESULTADOS OBTIDOS POR MOHRI COM O FSM LIBRARY ...................................................................49 


\section{Lista de Tabelas}

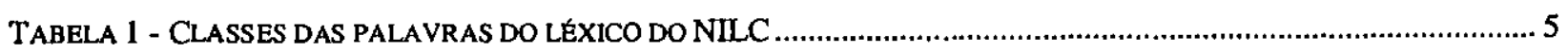

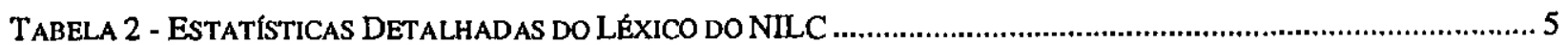

TABELA 3 - ESTATÍSTICAS PARA OS VoCABULARIOS E OS AUTÓMATOS ................................................................... 20

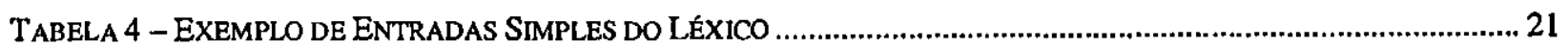

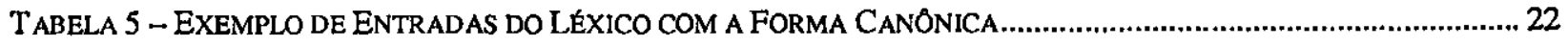

TABELA 6 - EXEMPLO DE ENTRADAS COMPLETAS DO LÉXICO ……........................................................................ 22

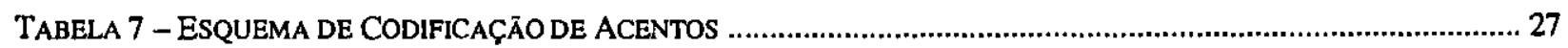

TABELA 8 - EXEMPLO DE CODIFICAÇÃO DOS ACENTOS AO FINAL DA PALAVRA

TABELA 9 - DADOS SOBRE OS LÉXICOS USADOS NOS TESTES................................................................................ 41

TABELA 10 - ENTRADAS DO LÉXICO DO NILC E RESPECTIVAS CONVERSÕES PARA O LÉXICO OTIMIZADO.................... 45

TABELA 11 - DESCRIÇÃO DOS LÉXICOS UTILIZADOS NOS TESTES DO FORMATO............................................................ 47

TABELA 12 - RESULTADOS DA CONVERSÃo DAS PALAVRAS DE LEX1 E LEX10 .................................................... 47

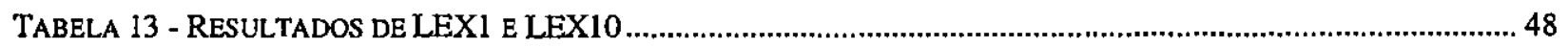

TABELA 14 - COMPAÇĀO DE LEX*.DIR E LEX*.FULL COM LEX*.W..................................................................... 48 
Aplicações de Processamento de Língua Natural (PLN), como revisores ortograficos, gramaticais e tradutores, geralmente precisam consultar extensos dicionários contendo, por exemplo, informações morfossintáticas de várias centenas de milhares de palavras de uma língua. Autômatos finitos, largamente utilizados na construção de eficientes analisadores léxicos para compiladores, apresentam-se como otimos candidatos para o problema de representação desse tipo de léxico de língua natural. Este trabalho investigou os métodos de codificação de léxicos utilizando autômatos finitos, as técnicas de minimização de autômatos determinísticos acíclicos e as estruturas de dados necessárias para uma representação compacta, resultando em um sistema computacional eficiente e versátil de representação de grandes léxicos de língua natural. Um léxico de mais de 430.000 palavras da língua portuguesa pode ser convertido em um autômato de menos de $220 \mathrm{~Kb}$, em menos de 5 minutos usando um computador doméstico. 
Natural Language Processing (NLP) applications, such as speller and grammar checkers and translation systems, need to search very large dictionaries which contain morphosyntactical and/or semantic information of several hundreds of thousand words of a given language. Finite Automata are often used in efficient scanners for compilers and are also good candidates for representing dictionaries. This work has investigated methods for representing dictionaries using finite automata, techniques for minimizing acyclic deterministic finite automaton, and adequate data structures for a compact representation. The resulting system is able to represent a dictionary of 430,000 Brazilian Portuguese words in a $220 \mathrm{~Kb}$ automaton, by using a standard home computer and spending less than five minutes. 


\section{Introdução}

A representação de grandes dicionários de língua natural, principalmente nos casos em que se trabalha com vários milhões (ou dezenas de milhões) de palavras, é um interessante problema computacional a ser tratado dentro da área de Processamento de Língua Natural (PLN). Autômatos finitos (AFs), largamente usados na construção de compiladores [AHO86, HOP79], são excelentes estruturas para representação desses dicionários, permitindo acesso direto aos às palavras e seus possíveis atributos (gênero, número, grau, etc) [APP88; GRO89; KOW93; MOH95; NUN96; KOW98].

Um dicionário contendo mais de 430.000 palavras da língua portuguesa sem atributos, cuja representação em formato texto ocupa mais de $4.5 \mathrm{Mb}$, pode ser convertido em um AF compactado de apenas $218 \mathrm{~Kb}$, conforme será apresentado (o processo de conversão para esse caso levou 4:17Seg, rodando em um Pentium166/Linux).

\subsection{Objetivos}

Esse trabalho tem por objetivo investigar métodos eficientes de construção, representação e minimização de AFs de grande porte (dezenas de milhões de estados), a fim de propor um conjunto de estruturas e algoritmos para criação de um sistema eficiente e versátil de representação de grandes léxicos de língua natural.

Outro objetivo é o de investigar métodos de representação para os atributos das entradas léxicas, de forma a permitir a criação de um formato otimizado capaz de ser inserido diretamente no $\mathrm{AF}$, com o menor impacto possível no tamanho final desse último.

Será também desenvolvido um protótipo do sistema, para efeito de testes e confirmação de eficiência do sistema.

\subsection{Organização do Trabalho}

Esse trabalho se encontra dividido da seguinte forma: o capítulo 2 descreve, de forma geral, o que é um léxico e suas formas tradicionais de representação, além de introduzir o léxico 
do NILC (que será usado no decorrer desse trabalho); o capítulo 3 discorre sobre AFs (definições, forma de representação, minimização e cita alguns pacotes de manipulação disponíveis); no capítulo 4 são resumidos dois trabalhos importantes da área, além de outros trabalhos relacionados; o capítulo 5 descreve o sistema de representação de AFs que está sendo proposto; o capítulo 6 introduz uma alternativa do formato para representação de atributos; e, finalmente, o capítulo 7 apresenta as conclusões, contribuições e trabalhos futuros. 


\section{Léxicos}

O léxico consiste de uma lista de palavras com zero ou mais informações associadas, tais como sua categoria sintática, gênero, número e forma canônica, entre outras. Em PLN, o léxico representa o vocabulário (ou dicionário) que será utilizado pelo sistema, e por isso sua abrangência depende do tipo de aplicação que o utiliza.

\subsection{Estruturas}

Os léxicos podem ser representados de várias formas, de acordo com o seu tamanho e aplicação a que se destinam.

A forma mais simples de representação léxica é através de arquivos texto, que apesar de simples e não otimizada, é bastante usada. Problemas começam a ocorrer com o crescimento do número de entradas lexicais (lexemas), pois passa a ser difícil (senão impossível) manipular esse arquivo. Mas este formato é excelente para importação e exportação de léxicos entre diferentes sistemas, devido à sua inerente simplicidade.

Outra forma de representação léxica muito usada é através de base de dados, onde todo o trabalho de armazenamento e indexação é feito pelo Sistema Gerenciador de Banco de Dados (SGBD). Mesmo não se obtendo uma taxa muito alta de velocidade de acesso, e com uma alta taxa de ocupação em disco, esse sistema é atraente pela capacidade de executar complexas buscas, por possibilitar vários usuários trabalharem ao mesmo tempo no mesmo léxico (através de um SGBD de arquitetura cliente-servidor), pela fácil manutenção do léxico, e pela facilidade no desenvolvimento de softwares para manipulação do léxico (usando ferramentas $\mathrm{RAD}^{\prime}$ ).

Entretanto, aplicações que necessitem acessar léxicos de forma rápida e otimizada precisam que esses sejam implementados de uma forma bem eficiente. Neste ponto, a questão do tamanho começa a representar um problema, pois passa a ser desejável que o léxico resida totalmente na memória principal da máquina, e as formas de representação citadas acabam não

\footnotetext{
' RAD - Rapid Application Development, ferramentas de desenvolvimento de software como, por exemplo, o Visual Basic da Microsoft e o Delphi da Inprise (antiga Borland)
} 
sendo aplicáveis nesse caso. Assim, é necessária a utilização de estruturas de dados especiais para esse tipo de representação. Existem várias alternativas, que podem ser usadas separada ou combinadamente: árvores, tries, tabelas hash, autômatos, listas, redes neurais, entre outras. Em geral a solução adotada depende muito das características do léxico a ser representado e no tipo de manipulação que será efetuada.

\subsection{O Léxico do NILC}

O Núcleo Interinstitucional de Lingüística Computacional (NILC), durante o convênio entre a Universidade de São Paulo (USP) e a Itautec-Philco, criou um léxico da língua portuguesa do Brasil com cerca de 1.500 .000 lexemas, gerados (via flexão e derivação) a partir de cerca de 100.000 lemas ou formas canônicas. Cada lexema pode pertencer a uma ou mais classes, de 13 disponíveis, cada uma com atributos distintos [NUN96]. Esse léxico será utilizado nos testes e exemplos citados neste trabalho. Segue um rápido exemplo de algumas entradas desse léxico:

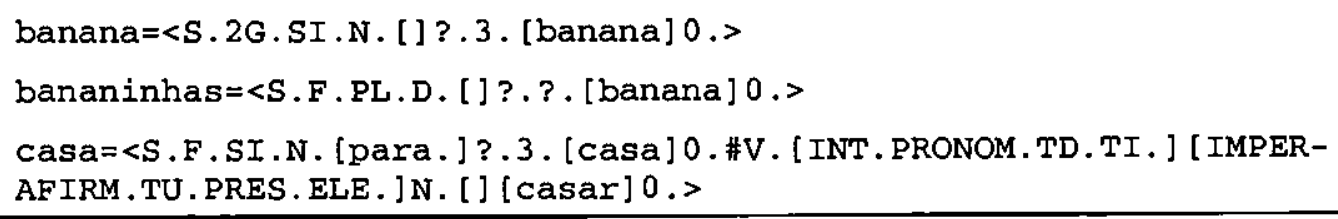

Neste exemplo, as duas primeiras entradas identificam substantivos (singular normal e plural diminutivo, respectivamente), associados à mesma forma canônica ([banana]). A terceira entrada (casa) identifica uma palavra que é usada tanto como substantivo (feminino, singular, regido pela preposição para, derivado da forma canônica [casa]) quanto como verbo (intransitivo, pronominal, transitivo direto e transitivo indireto, que ocorre na segunda pessoa do singular do imperativo afirmativo e na terceira pessoa do singular do presente do verbo casar).

A Tabela 1 apresenta as classes possíveis para as palavras do léxico do NILC. E, nos apêndices, pode ser encontrada a notação BNF completa do formato desse léxico.

A partir de um snapshot do léxico consolidado de Fevereiro/1999, foram compiladas algumas estatísticas expostas na Tabela 2. Esse léxico contém 1.506 .765 entradas compostas distintas (89Mbytes), como as citadas no primeiro exemplo dessa seção. 
Tabela 1 - Classes das palavras do léxico do NILC

\begin{tabular}{|c|c|}
\hline Classe & Abreviatura \\
\hline Substantivo & S. \\
\hline Artigo & ART. \\
\hline Preposição & PREP. \\
\hline Numeral & NUM. \\
\hline Pronome & PRON. \\
\hline Verbo & V. \\
\hline Adjetivo & ADJ. \\
\hline Conjunção & CONJ. \\
\hline Advérbio & ADV. \\
\hline Nome Próprio & NOM. \\
\hline Prefixo & PREF. \\
\hline Sigla & SIGL. \\
\hline Abreviatura & ABREV. \\
\hline
\end{tabular}

Tabela 2 - Estatisticas Detalhadas do Léxico do NILC

\begin{tabular}{|c|r|r|r|r|}
\hline Classe & \multicolumn{2}{|c|}{ Quantidade $^{2} / \%$} & \multicolumn{2}{c|}{ Derivações $^{3} / \%$} \\
\hline Substantivo & 57.862 & 3,7258 & 105.074 & 3,4438 \\
\hline Artigo & 8 & 0,0018 & 16 & 0,0018 \\
\hline Preposição & 148 & 0,0108 & 268 & 0,0098 \\
\hline Numeral & 235 & 0,0158 & 430 & 0,0148 \\
\hline Pronome & 252 & 0,0168 & 534 & 0,0178 \\
\hline Verbo & 1.426 .476 & 91,8398 & 2.817 .374 & 92,3148 \\
\hline Adjetivo & 59.624 & 3,8398 & 111.202 & 3,6448 \\
\hline Conjunção & 52 & 0,0038 & 192 & 0,0068 \\
\hline Advérbio & 2.673 & 0,1728 & 5.730 & 0,1888 \\
\hline Nome Próprio & 5.143 & 0,3318 & 9.700 & 0,3188 \\
\hline Prefixo & 73 & 0,0058 & 104 & 0,0038 \\
\hline Sigla & 459 & 0,0308 & 912 & 0,0308 \\
\hline Abreviatura & 228 & 0,0158 & 416 & 0,0148 \\
\hline TOTAL & 1.553 .233 & 3.051 .952 \\
\hline
\end{tabular}

${ }^{2} \mathrm{O}$ valor total é maior que o número de entradas distintas do léxico devido ao fato de algumas entradas pertencerem a duas ou mais classes diferentes (ex: "casa" que além de substantivo fem. sing. também é verbo na $3^{\mathrm{a}}$ pessoa e no imperativo).

${ }^{3} \mathrm{Na}$ derivação, todas as entradas são separadas pelas suas variações de gênero, número, grau, pessoa, tempo, etc. Um verbo, por exemplo, é derivado em mais de 220 entradas distintas (pouco mais de 50 flexões normais dos verbos, e as outras decorrentes das ênclises e mesóclises). 


\section{Autômatos Finitos}

Autômatos finitos são largamente utilizados na construção de compiladores, onde exercem a função de eficientes analisadores léxicos [AHO86]. Nesta seção serão apresentadas as notações e definições básicas, os métodos de representação alguns dos algoritmos de minimização de autômatos finitos.

\subsection{Notações e Definições}

Nesta seção serão informalmente introduzidas algumas notações e definições relevantes a linguagens e autômatos finitos.

\section{Alfabeto, Palavras e Linguagens}

Seja $A$ um conjunto finito, chamado alfabeto. Seus elementos são chamados letras e, por conveniência, serão denotá-los por letras minúsculas $(a, b, c, \ldots)$. Será assumida a existência de uma ordem no alfabeto.

Uma palavra é uma sequiência finita de letras. O comprimento de uma palavra $w$ é denotado por $|w|$, e sua $n$-ésima letra por $w_{n}$. O produto de duas palavras $u$ e $v, u v$, representa a palavra obtida escrevendo-se seqüencialmente as letras de $u$ e depois as letras e $v$. O conjunto de todas as palavras é representado por $A^{*}$ e a palavra vazia por $\varepsilon$. Diz-se que uma linguagem é qualquer subconjunto de $A^{*}$.

Uma palavra $f$ é dita um fator de uma palavra $w$ se $w=x f y$ para algum $x, y \in A^{*}$. É um fator próprio de $w$ se $w \neq f$, um prefixo de $w$ se $x=\varepsilon$, e um sufixo de $w$ se $y=\varepsilon$

\section{Autômato Finito}

Um autômato finito $M$ (Figura 1) é uma quíntupla $\left(Q, \Sigma, \delta, q_{0}, F\right)$ onde

$Q$ é um conjunto finito de estados;

$\Sigma$ é o alfabeto de entrada;

$\delta: Q \times \Sigma \rightarrow Q$ representa a função de transição de estados; 
$q_{0} \in Q$ é o estado inicial do autômato; e

$F \subseteq Q$ é o conjunto de estados finais.

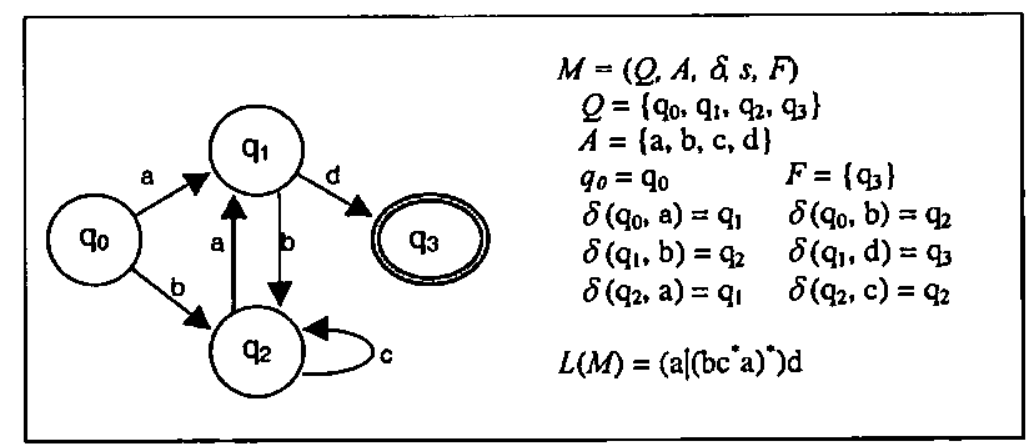

Figura 1 - Exemplo de Autômato Finito Deterministico

A função de transição $\delta$ não é necessariamente uma função total, isto é, pode não estar definida para todos os pares de estados e símbolos de entrada em $Q \times \Sigma$. Se $\delta$ é uma função total então diremos que $M$ é um autômato finito completo.

Um autômato finito $M$ é dito determinístico se, dado um estado $q \in Q$ e um símbolo $a \in \Sigma$ quaisquer, não existe mais do que uma transição definida pela função $\delta$ para este par de estado/símbolo. Caso contrário o autômato é dito não determinístico.

Diz-se que um autômato finito é acíclico quando este não apresenta ciclos, ou seja, a partir de um estado $q \in Q$ qualquer, a função de transição deve definir valores tais que este estado não seja mais alcançado. Se existe apenas um estado final (sem transições a partir dele) e nenhuma transição leva ao estado inicial, diz-se que o autômato é normalizado.

O estado alcançado pela transição do símbolo $a \in \Sigma$ a partir do estado $q \in Q$ é denotado por $q . a=\delta(q, a)$. Esta notação é transitiva: se $w \in \Sigma^{*}$ é uma palavra então $q . w$ denota o estado alcançado usando-se as transições simbolizadas por cada letra $w_{l}, w_{2}, \ldots, w_{n}$ de $w$.

Uma palavra $w$ é aceita por um autômato finito $M$ se existe um caminho definido pela função de transição para as letras de $w$, do estado inicial até algum estado final de $M$ (ou, de outra forma, se $q_{0 . w} \in F$ ). A linguagem aceita (ou reconhecida) por um autômato finito $M$ é denotada por $L(M)$. Diz-se que dois autômatos finitos $M$ e $N$ são equivalentes se $L(M)=L(N)$. 
Um autômato é dito mínimo se ele for determinístico e, se comparado a todos os autômatos equivalentes a ele, possuir o menor número de estados.

\subsection{Representação de Autômato Finito}

De modo geral, o problema de representação de um autômato finito reduz-se ao problema de representar a função de transição $\delta$ do autômato. Nesta seção serão expostos os métodos de representação tradicionais.

\section{Matriz de Transições}

Este é o método mais simples para se representar um autômato finito, e consiste em se armazenar os valores da função de transição em uma matriz $\Sigma \times Q$ (Figura 2). Entretanto, este método só deve ser utilizado para autômatos com poucos estados e alfabetos pequenos, pois apesar do tempo de acesso ser $O(1)$, o requisito de espaço é $O(|\Sigma| \times|Q|)$, para um autômato determinístico.

\begin{tabular}{|c|c|c|c|c|}
\hline & $q_{0}$ & $q_{1}$ & $q_{2}$ & $q_{3}$ \\
\hline$a$ & $q_{1}$ & $\cdots$ & $q_{1}$ & $\cdots$ \\
\hline$b$ & $q_{2}$ & $q_{2}$ & $\cdots$ & $\cdots$ \\
\hline c & $\cdots$ & $\cdots$ & $q_{2}$ & $\cdots$ \\
\hline$d$ & $\cdots$ & $q_{3}$ & $\cdots$ & $\cdots$ \\
\hline
\end{tabular}

Figura 2 - Exemplo de Matriz de Transições

\section{Listas de Adjacência}

Uma forma tradicional de representação de grafos é utilizar listas de adjacência, e isto também pode ser aplicado a autômatos. Assim, para cada estado $q \in Q$ do autômato, associa-se um conjunto de pares $(a, \delta(q, a))$, para toda $\delta(q, a)$ definida (Figura 3). O requisito de espaço é $O(|Q|+|\delta|)$, e o tempo de acesso é $O(\log (\min (|Q|,|\delta|)))$. 


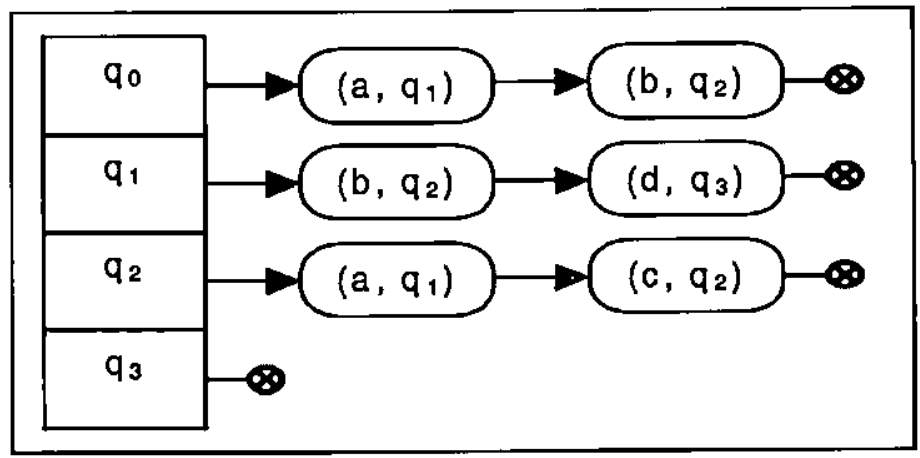

Figura 3 - Exemplo de Lista de Adjacência

\section{Lista de Transiçôes}

Este método consiste em implementar a lista de transições definida pela função $\delta$ do autômato. Cada $\delta(p, a) \rightarrow q$ é representado na forma de uma tripla $(p, a, q)$, e o requisito total de espaço é $O(|\delta|)$. Assume-se que esta lista será armazenada em uma tabela hash para que seja possível calcular rapidamente a função de transição. Desta forma, dada uma função hash eficiente, na média o tempo de acesso à função de transição será constante.

\begin{tabular}{|c|c|c|}
\hline $\boldsymbol{p}$ & $\boldsymbol{a}$ & $\boldsymbol{q}$ \\
\hline $\mathrm{q}_{0}$ & $\mathrm{a}$ & $\mathrm{q}_{1}$ \\
\hline $\mathrm{q}_{0}$ & $\mathrm{~b}$ & $\mathrm{q}_{2}$ \\
\hline $\mathrm{q}_{1}$ & $\mathrm{~b}$ & $\mathrm{q}_{2}$ \\
\hline $\mathrm{q}_{1}$ & $\mathrm{~d}$ & $\mathrm{q}_{3}$ \\
\hline $\mathrm{q}_{2}$ & $\mathrm{a}$ & $\mathrm{q}_{1}$ \\
\hline $\mathrm{q}_{2}$ & $\mathrm{c}$ & $\mathrm{q}_{2}$ \\
\hline
\end{tabular}

Figura 4 - Exemplo de Lista de Transiçōes

\subsection{Minimização de Autômato Finito Determinístico}

A minimização de autômato finito determinístico é um problema que vem sendo estudado desde os anos 50. Basicamente o problema consiste em encontrar o único autômato finito determinístico mínimo que aceita a mesma linguagem que um dado autômato finito determinístico. Algoritmos para resolver este problema são usados em aplicações desde construção de compiladores até minimização de circuitos de hardware [WAT93a]. 
De forma geral, algoritmos de minimização de autômatos trabalham identificando conjunto de estados equivalentes e "fundindo-os" em um só, numa técnica conhecida como merge. Dois estados $p$ e $q \in Q$ são equivalentes quando $\delta(p, a)=\delta(q, a)$, para todo $a \in \Sigma$. O merge dos estados $p$ e $q$ é feito adaptando-se a função de transição de tal forma que as transições que antes levavam a $q$ devem agora levar a $p$ (Figura 5).

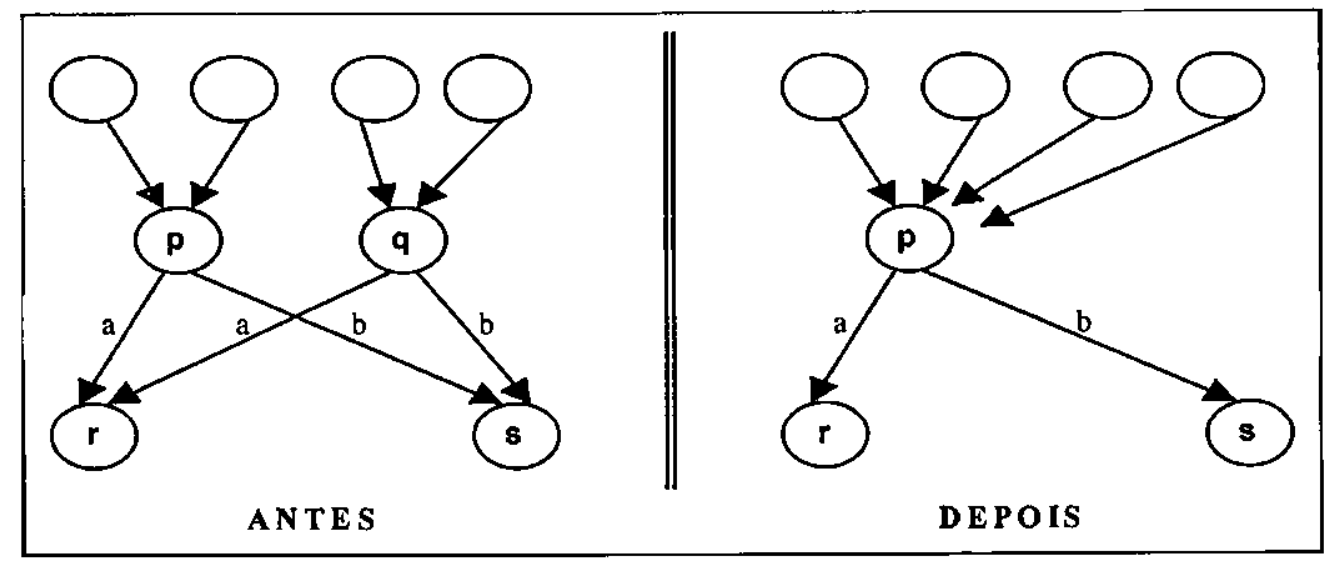

Figura 5 - Merge de Dois Estados Equivalentes

Existem quatro algoritmos clássicos de minimização de autômatos finitos determinísticos baseados na técnica de equivalência de estados:

- Algoritmo de Wood [WOO87] - de fácil entendimento, realiza a minimização do autômato em tempo $O\left(|Q|^{3}\right)$.

- Algoritmo de Aho-Setti-UlIman [AHO86] - capaz de realizar a minimização do autômato finito em tempo $O\left(|Q|^{2}\right)$, é o método mais utilizado na prática, dada sua boa relação custo-benefício (em termos de implementação). Calcula uma relação de equivalência nos estados, que indica quais estados são indistinguíveis

- Algoritmo de Hopcroft [HOP71; GRI73; WAT93a] - este é o melhor algoritmo conhecido para minimização de um autômato finito determinístico, em termos de tempo de execução: $O(|Q| \log |Q|)$. Também é o mais complexo.

- Algoritmo de Hopcroft-Ullman [HOP79] - Calcula o complemento da relação calculada pelo algoritmo de Aho-Sethi-Ullman. Como o algoritmo atravessa as transições do autômato finito determinístico na direção reversa, ele tem uma desvantagem de tempo de execução na maioria das implementações de autômato finito determinístico. 
O único método de minimização que não se baseia na equivalência de estados é o Método de Brzozowski [BRZ62; WAT93a]. Neste método, o autômato (que não precisa ser determinístico) é revertido, determinizado, revertido novamente e mais uma vez determinizado. Sua implementação é relativamente simples, uma vez que consiste apenas nas operações de reversão e determinização do autômato.

\subsection{Pacotes para Manipulação de Autômatos Finitos}

Existem vários pacotes para manipulação de autômatos finitos. Nesta seção serão apresentados alguns deles, que se destacam pela boa cobertura de autômato finito determinístico e pela implementação de algoritmos de minimização de autômatos.

Embora para o problema de representação de grandes léxicos seja mais eficiente utilizar métodos especiais do que os métodos genéricos (devido a todas as particularidades do autômato finito determinístico acíclico), estes pacotes são de grande valor para testes, protótipos e pesquisas sobre autômatos finitos.

\subsubsection{FSA Utilities}

FSA Utilities é uma coleção de utilitários para manipular autômatos e transducers de estado finito. Manipulações incluem determinização, minimização, composição, complementação, intersecção, etc. A ferramenta é implementada em SICStus Prolog, e existem várias ferramentas de visualização para o autômato [NOO97].

\section{Representação}

No FSA Utilities, um autômato finito é definido como um conjunto de cláusulas Prolog, usando as seguintes relações:

start (state). State é o estado inicial. Deve haver pelo menos um estado inicial. Múltiplos estados iniciais são permitidos.

final (State). State é um estado final. Pode haver qualquer número de estados finais.

trans (State0, Sym, state). Define uma transição do estado stateo para state associado ao símbolo sym. Pode haver qualquer número de transições. 
jump (State0, state). Define uma transição vazia ( $\varepsilon$-transição) do estado stateo para state. Pode haver qualquer número de saltos.

\section{Minimização}

A ferramenta suporta três diferentes implementações da operação de minimização:

1. Algoritmo de Hopcroft e Ullman (1979);

2. Método de Brzozowski (1962);

3. Algoritmo de Hopcroft (1971).

\section{Considerações}

Esta ferramenta é bastante útil para testes e experimentação de novas técnicas, embora não seja indicada para construção de programas práticos. Por ser implementado em Prolog, facilita a implementação de protótipos a partir de definições teóricas, além de a ferramenta poder ser utilizada na linha de comando, funcionando como filtro.

\subsubsection{FIRE Lite}

FIRE Lite é um pacote em C++ que implementa algoritmos de autômato finito e expressões regulares, desenvolvido por Bruce Watson na Universidade de Tecnologia de Eindhoven. $O$ pacote provê classes de objetos e algoritmos de um nível suficientemente baixo tal que eles podem ser usados na maioria das aplicações que requerem autômato finito ou expressões regulares. Quase todos os algoritmos definidos em [WAT93a; WAT93b] são implementados [WAT96].

\section{Vantagens}

A seguir são citadas algumas vantagens e diferenças do uso do pacote FIRE Lite em relação a outros pacotes do gênero [WAT96]:

- FIRE Lite não provê uma interface de usuário. Ao invés disso, FIRE Lite é estritamente uma biblioteca de classes e algoritmos para serem usados em aplicações; 
- O pacote é implementado para ser eficiente. Ao contrário de outros, que são implementados com objetivos educacionais, a implementação usando FIRE Lite é suficientemente eficiente para poder ser utilizada em aplicativos práticos;

- FIRE Lite provê implementações de quase todos os algoritmos conhecidos de construção de autômato finito, ao contrário dos outros que geralmente apresentam apenas um.

\section{Minimização}

O pacote inclui 5 algoritmos de minimização de autômato finito determinístico, a saber:

1. Algoritmo de Brzozowski;

2. Algoritmo de Aho-Sethi-Ullman;

3. Algoritmo de Hopcroft-Ullman;

4. Algoritmo de Hopcroft ;

5. Algoritmo de B.W. (algoritmo especial do autor [WAT96]);

\section{Consideraçōes}

Este pacote é particularmente interessante por três motivos: primeiramente, ele foi escrito pelo autor de excelentes taxionomias de construção e minimização autômato finito [WAT93a; WAT93b]; segundo, pela ênfase em eficiência, o que o torna atrativo para protótipos mais robustos; e, por fim, por ele ter sido desenvolvido em $\mathrm{C}++$, a mesma linguagem que será usada neste projeto.

\subsubsection{Grail}

O pacote Grail [RAY93], desenvolvido na Universidade de Waterloo por Darrell Raymond e Derick Wood, é um ambiente de computação simbólica para máquinas de estados finitos, expressões regulares, e outros objetos de teoria de linguagem formal. Capaz de realizar conversão, minimização, complemento e várias outras operações sobre autômatos, Grail é indicado para ensino, além de ser eficiente. Ele pode manipular autômatos com cerca de 100,000 estados e dicionários de 20,000 palavras. 
Grail apresenta duas interfaces:

1. Um conjunto de programas filtros: cada filtro implementa uma operação elementar em autômato finito ou expressão regular. Essas operações incluem conversões de expressões regulares para autômato finito, minimização de autômato finito, etc. Os filtros podem ser combinados para obter-se operações mais complexas. Esta interface satisfaz os dois primeiros objetivos (de três) do Grail: prover um mecanismo de pesquisa de algoritmos teóricos, e facilitar o ensino de teoria de linguagem.

2. Uma biblioteca de classes $\mathrm{C}^{++}$provendo uma grande variedade de objetos e algoritmos. Esta interface satisfaz o terceiro objetivo de Grail: um sistema eficiente para uso em aplicativos práticos.

\section{Considerações}

Grail é um bom pacote para fins educacionais, mas não é capaz de tratar problemas de autômatos extremamente grandes como os usados em grandes léxicos de língua natural.

\subsubsection{FSM Library}

Esse é um pacote desenvolvido pela divisão de pesquisa da AT\&T para manipulação de autômatos finitos e transducers, com o objetivo de lidar com problemas de grande porte de forma eficiente.

Pode ser usado diretamente através de seus utilitários, ou por um programa em C, por exemplo, através de sua interface de programação. Implementa mais de 30 funções de manipulação de $\mathrm{AF}$.

Maiores informações e licença para download estão disponíveis no site da $A T \& T$ Research em: http://www. research. att.com/sw/tools/fsm . 


\section{Considerações}

Essa ferramenta é a que mais se aproxima do sistema sendo proposto nesse trabalho, embora seja uma ferramenta de tratamento genérico de autômatos. Apesar da AT\&T disponibilizar apenas as ferramentas em formato binário, e não a biblioteca de programação, essa ainda é uma ótima ferramenta para manipular autômatos de grande porte. Alguns resultados de tratamento de léxicos usando essa ferramenta são expostos na seção 6.4 (página 48). 


\section{Uso de AF para Representação de Léxicos}

Nesse capítulo serão discutidos alguns trabalhos importantes relacionados ao uso de AF para representação de léxicos de língua natural. Na seção 4.1 está descrito o trabalho de Kowaltowski, Lucchesi e Stolfi (KLS), pesquisadores do IC-UNICAMP, que desenvolvem um excelente trabalho nessa área; a seção 4.2 resume o trabalho de Dominique Revuz sobre minimização de AF determinístico acíclico; por fim, a seção 4.3 cita alguns outros trabalhos relacionados, como o sistema INTEX do LADL/University Paris 7.

\subsection{O Trabalho de K.L.S.}

Inicialmente motivados pelo problema de implementar um eficiente aconselhador ortográfico para a Língua Portuguesa, Kowaltolski e Lucchesi (e depois também Stolfi), pesquisadores do IC-Unicamp, desenvolveram um importante trabalho sobre o uso de autômato finito para representação de grandes vocabulários [KOW93; KOW95a; KOW95b; KOW98].

O sistema desenvolvido por estes pesquisadores permitiu a representação de um léxico simples (apenas palavras, sem atributos) de cerca de 200.000 palavras em um autômato de $124 \mathrm{~Kb}$ [KOW93], e recentemente um léxico completo (palavras com atributos sintáticos e gramaticais) de cerca de 2.000 .000 de entradas foi codificado em um autômato de menos de $1,1 \mathrm{Mb}$ [KOW98].

\subsubsection{Implementação do Autômato}

A construção do autômato ocorre de acordo com o seguinte algoritmo [KOW93]:

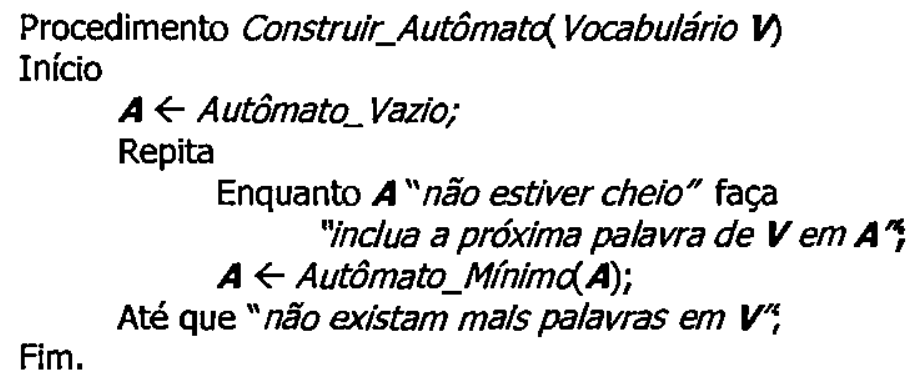


Após a primeira execução do laço enquanto...faça o autômato $\boldsymbol{A}$ é na verdade uma árvore digital, como pode ser observado na Figura 6. Esta árvore pode crescer muito rapidamente: para o léxico de cerca de 200.000 palavras citado anteriormente, a árvore teria mais de 600.000 vértices. Por isso o laço externo repita...até é necessário. O processo de minimização aproveita o fato de o autômato ser acíclico e usa um algoritmo de ordem de tempo linear no tamanho do autômato. Após a minimização, o mesmo autômato toma a forma da Figura 7.

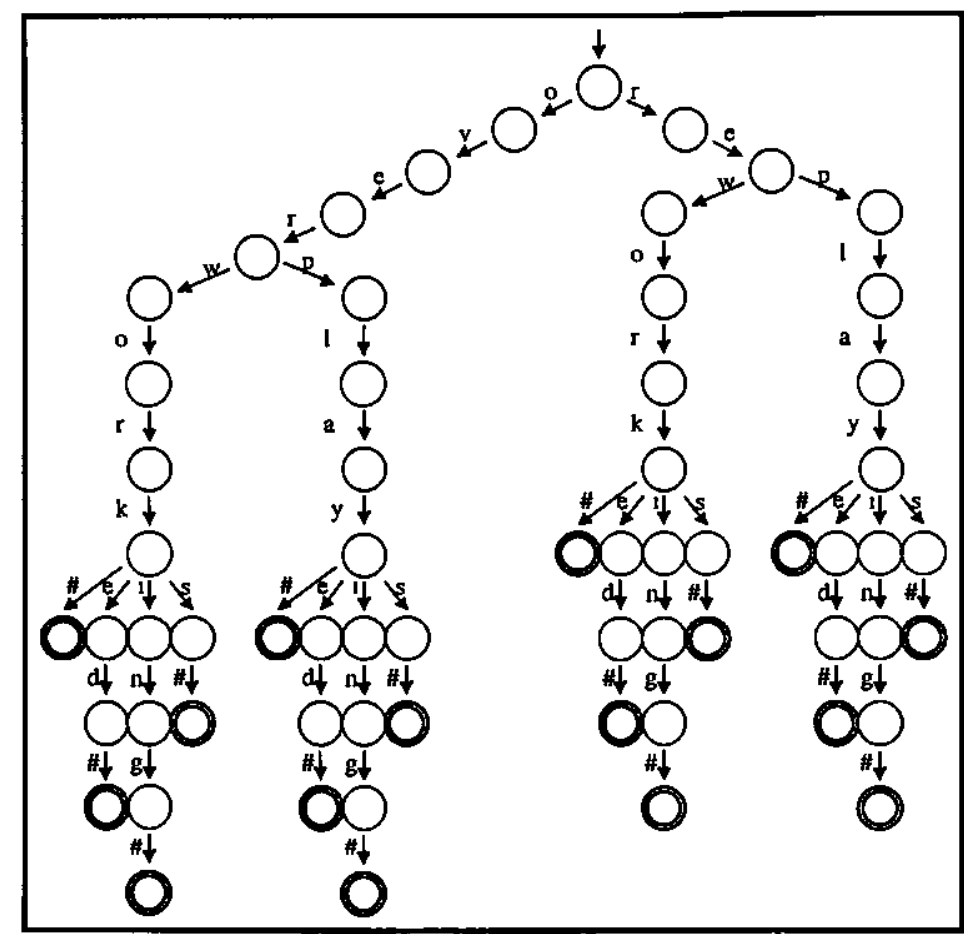

Figura 6 - Autômato para todas as formas dos verbos rework, replay, ovenwork e overplay

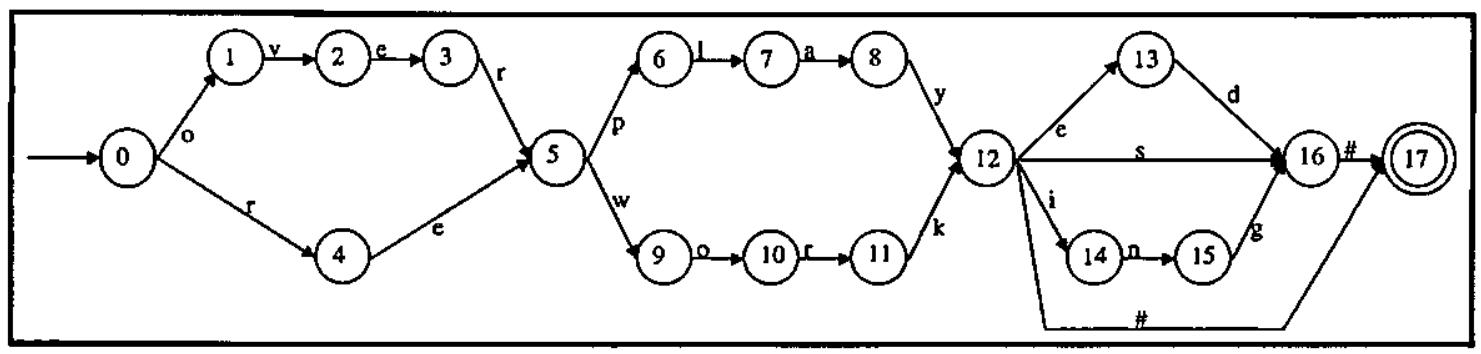

Figura 7 - Autómato Finito Deterministico Acíclico Mínimo criado a partir da Figura 6

Cada estado é representado como um vetor de $M$ entradas (onde $M$ é o tamanho do alfabeto), sendo que a maioria das entradas corresponde a transições não existentes. 
Aproveitando-se deste fato, pode-se definir uma estrutura melhor, onde cada estado está associado a um vetor de $M$ bits que seleciona as transições válidas para o estado.

O algoritmo de busca para uma dada palavra é muito eficiente. Começando pelo estado inicial, ele percorre o autômato utilizando letras consecutivas da palavra para selecionar as transições, até que um estado final é alcançado ou não existam mais transições válidas (em outras palavras, ou a palavra pertence ao vocabulário ou não pertence).

\subsubsection{Autômato Binário}

A experiência demonstra que o autômato para um vocabulário de língua natural é muito esparso, no seguinte sentido: para a grande maioria dos estados em $q \in Q$ e para quase todas as . letras $a \in \Sigma$, a função $\delta(q, a)$ não está definida (ou seja, levam ao estado de rejeição). No caso da Língua Portuguesa, por exemplo, quase metade dos estados têm apenas uma transição válida, e aproximadamente $70 \%$ dos estados tem no máximo duas transiçōes válidas. Essa característica leva a um esquema de representação onde cada estado $q$ é representado por uma lista de valores que representam suas transições válidas [KOW95a].

Com essa representação, pode-se ver os nós das listas de transições como "estados" de uma espécie de autômato, onde cada estado tem apenas uma transição de sucesso (associada a uma letra), e uma transição de falha (representada por um ponteiro para o próximo no). Chamase este dispositivo de autômato binário (ver abaixo). Considera-se também, para esse autômato, a existência de apenas um estado final, denotado $q_{a}$ (estado de aceitação), e apenas um estado de rejeição (chamado de $q_{r}$ ). Todas as transições de $q_{a}$ e $q_{r}$ levam a $q_{r}$, sendo este o único estado a admitir ciclos.

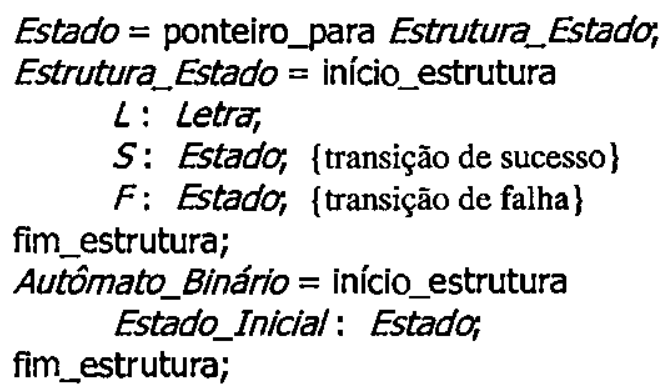


Usando a estrutura definida acima, pode-se calcular a função de transição do autômato $(\delta: Q \times \Sigma \rightarrow \Sigma)$ da seguinte forma:

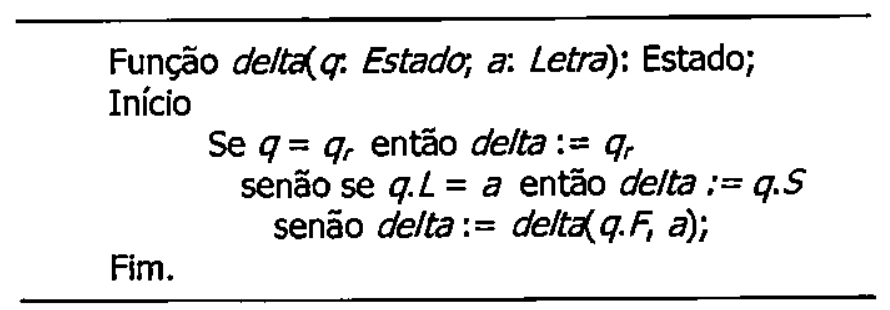

\section{Representação Vetorial}

Em algumas situações é interessante trocar a estrutura dinâmica por uma representação estática baseada em vetor. Para isso, enumera-se os estados do autômato binário com números inteiros consecutivos, e armazena-se todos as estruturas Estrutura_Estado em um vetor indexado pelo número do estado.

Neste esquema, é conveniente atribuir o índice 0 para o estado de rejeição $\left(q_{r}\right)$, e o índice 1 para o estado de aceitação $\left(q_{a}\right)$, e desta forma estas duas entradas podem ser omitidas no vetor. Assim, se o $i$-ésimo estado é $q$, o $i$-ésimo elemento do vetor contém a tripla $(L, S, F)$, onde os campos $S$ e $F$ agora são números de estados, e não mais ponteiros.

Usando-se o conceito de ordenação topológica, pode-se também assumir a existência de uma ordem total no conjunto de estados $Q$ do autômato tal que $\delta(q, a) \leq q$, para quaisquer $q \in Q$ e $a \in \Sigma$. Para isso, ao construir a representação vetorial do autômato binário, enumera-se os estados de $Q$ como $\{0,1, \ldots, n\}$ de forma que 0 é o estado de rejeição, 1 é o estado de aceitação, $n$ é o estado inicial, e os campos $S$ e $F$ na entrada $i$ do vetor $(i>1$ ) são ambos estritamente menores que $i$.

\section{Considerações}

Este tipo de autômato é atraente pela sua simplicidade de implementação e manipulação. $O$ algoritmo de minimização pode trabalhar simplesmente identificando entradas repetidas no vetor e realizando um merge, embora o uso de um algoritmo de reordenação das listas de transições possa tornar o processo de minimização mais eficiente. Mas encontrar um autômato binário verdadeiramente mínimo parece ser um problema NP-completo [KOW95a]. 
Kowaltowski, Lucchesi e Stolfi sugerem nesse artigo um algoritmo heurístico para minimização de autômato binário.

\subsubsection{Resultados Práticos}

Os testes principais foram aplicados a um vocabulário de 81.000 palavras do Inglês e outro de 206.000 palavras do Português [KOW93]. Apesar deste último ser maior, o autômato que o representa é menor que o autômato para o vocabulário do Inglês, devido ao fato do grande número de formas derivadas na Língua Portuguesa ${ }^{4}$.

A Tabela 3 apresenta algumas estatísticas desses testes, comparando-os em relação ao número de palavras (e tamanho do arquivo texto), e ao número de estados e transições e tamanho dos autômatos correspondentes. Também são indicados os resultados obtidos pela compactação dos dados utilizando os utilitários PKZIP e PKPAK (embora o autômato não seja efetivamente um mecanismo de compactação, mas sim de representação eficiente).

Tabela 3 - Estatísticas para os Vocabulários e os Autômatos [KOW93]

\begin{tabular}{|c|c|c|}
\cline { 2 - 3 } \multicolumn{1}{c|}{} & Inglês & Português \\
\hline Vocabulário & & \\
\hline Palavras & 81.142 & 206.786 \\
\hline Kbytes & 858 & 2,389 \\
\hline PKPAK & 313 & 683 \\
\hline PKZIP & 253 & 602 \\
\hline Autômato & & 17.267 \\
\hline Estados & 29.317 & 45.838 \\
\hline Transições & 67.709 & 124 \\
\hline Kbytes & 203 & 105 \\
\hline PKPAK & 173 & 109 \\
\hline PKZIP & 183 & \\
\hline
\end{tabular}

Também foi observado que o crescimento do autômato era quase linear caso as palavras fossem inseridas por ordem alfabética, o que não acontecia caso as palavras fossem inseridas em uma ordem randômica (neste caso, o autômato poderia chegar a ter até o dobro do tamanho, durante as inserções, para no final (após a minimização) se reduzir ao mesmo autômato da inserção alfabética) [KOW93]. 


\subsubsection{Codificação de Informações Lexicais no Autômato}

A codificação das informações lexicais deve ser bem organizada e estruturada de acordo com uma melhor taxa de aproveitamento do autômato. Considerando cada entrada do léxico como uma string $w$ (contendo a palavra a ser armazenada e sua classificação), quando esta string for inserida no autômato haverá uma melhor taxa de aproveitamento se:

1. O prefixo de $w$ puder ser reutilizado;

2. O sufixo de $w$ puder ser reutilizado;

A condição 1 está implicitamente definida, pois trabalhamos com um autômato determinístico, então se $x y$ e $x z \in \Sigma^{*}$ são palavras quaisquer que compartilham um mesmo prefixo $x$ então os estados do autômato relativos às transições para o prefixo $x$ serão comuns às duas palavras. Analogamente, a condição 2 ocorre para o sufixo comum $z$ de duas palavras $x z \mathrm{e}$ $y z \in \Sigma^{*}$ quaisquer, após o autômato ser minimizado.

Os atributos gramaticais de uma palavra podem ser codificados como tokens ligados à palavra. Para representar o substantivo menino e suas flexões, por exemplo, pode-se usar um esquema de codificação como o exemplificado na Tabela 4 [KOW98].

Desta forma, para se saber qual a classe gramatical da palavra menina, por exemplo, basta procurar por "menina:" no autômato e depois enumerar todos os sufixos possíveis.

Tabela 4 - Exemplo de Entradas Simples do Léxico

\begin{tabular}{|c|c|}
\hline ENTRADA & SIGNIFICADO \\
\hline menino:as & Substantivo masculino singular $(s a)$ \\
\hline menina:sb & Substantivo feminino singular $(s b)$ \\
\hline meninos:sc & Substantivo masculino plural $(s c)$ \\
\hline meninas:sd & Substantivo feminino plural $(s d)$ \\
\hline
\end{tabular}

\footnotetext{
${ }^{4}$ Por exemplo, um verbo regular do Português apresenta 51 flexōes distintas, cujos sufixos podem ser compartilhados entre todos os outros verbos regulares.
} 
Entretanto, para algumas pesquisas é preciso incluir mais uma informação às entradas do léxico: a forma canônica. Uma forma eficiente de se codificar esta informação é adicioná-la à string da entrada léxica, de forma a distinguí-la da palavra da entrada pelos últimos caracteres (Tabela 5). Na entrada "meninas:sd:2o", por exemplo, a forma canônica foi obtida removendo-se os últimos 2 caracteres de "meninas" e acrescentando-se " $o$ ", e este procedimento é denotado por ":2o" na string da entrada léxica.

Tabela 5 - Exemplo de Entradas do Léxico com a Forma Canônica

\begin{tabular}{|c|c|}
\hline ENTRADA & FORMAÇÃO DA CANÔNICA \\
\hline menino:sa:0 & menino $-"$ " $+"$ "' $=$ menino \\
\hline menina:sb:1o & menina $-\mathrm{a}+\mathrm{o}=$ menino \\
\hline meninos:sc:1 & meninos $-\mathrm{s}+"$ "" $=$ menino \\
\hline meninas:sd:2o & meninas $-\mathrm{as}+\mathrm{o}=$ menino \\
\hline
\end{tabular}

Por fim, para podermos responder perguntas como: "Qual o plural de menina?", temos que obter a classificação e forma canônica de "menina" (":sb" e "menino", respectivamente), e então procurar pela entrada ": $s d$ " (feminino plural) da canônica "menino". Para que esta última operação seja efetuada de forma eficiente, deve-se incluir uma entrada adicional para cada entrada do léxico, a entrada reversa (Tabela 6).

$\mathrm{Na}$ entrada reversa, utiliza-se a mesma regra da entrada normal para obtenção da palavra a partir da canônica: subtrai-se zero ou mais letras do final da canônica e acrescenta-se zero ou mais caracteres para obter-se a palavra. $O$ fato de duplicarmos o número de entradas lexicais não faz duplicar o tamanho do autômato, pois os afixos das entradas são altamente reutilizados.

Tabela 6 - Exemplo de Entradas Completas do Léxico

\begin{tabular}{|c|c|}
\hline ENTRADA NORMAL & ENTRADA REVERSA \\
\hline menino:sa:0 & menino::sa:0 \\
\hline menina:sb:10 & menino::sb:1a \\
\hline meninos:sc:1 & menino::sc:0s \\
\hline meninas:sd:2o & menino::sd:1as \\
\hline
\end{tabular}


Seguindo-se este sistema, pode-se definir métodos de representação para vários outros atributos gramaticais, como exposto em [KOW98].

\subsection{Algoritmo de Minimização de Revuz}

Dominique Revuz (Universidade de Paris) apresenta em [REV92] um algoritmo linear para minimização de um autômato finito determinístico acíclico, que pode ser usado, em particular, para minimizar um autômato que representa um léxico.

Cada estado do autômato é associado a uma string descrevendo o autômato reduzido iniciado neste estado. Trabalhando nos níveis maiores (onde o nível é a maior distância até um estado final), o algoritmo gera rótulos que são criados a partir dos rótulos de seus estados seguintes. A cada nível, uma ordenação lexicográfica é aplicada à lista de rótulos e todos os estados com rótulos idênticos sofrem merge (tais estados são equivalentes). A associação dos rótulos é feita apenas uma vez em cada estado, e a ordenação é linear; assim, a complexidade geral é linear nos números de transições.

\subsubsection{O Algoritmo de Minimização}

Primeiramente é necessário definir a função peso em um autômato acíclico: para cada estado $s$ do autômato, coloca-se $\operatorname{peso}(s)=\max \{|w|$ tal que $s . w$ é final $\}$ (peso $(s)=$ comprimento do maior caminho iniciando em $s$ e chegando a um estado final). Esta função cria uma partição $P$ de $Q ; P_{i}$ irá denotar o conjunto de estados de peso $i$. Dizemos ainda que o conjunto $P_{i}$ é distinguivel se não existem estados equivalentes em $P_{i}$.

Assim, se cada partição $P_{j} \operatorname{com} j<i$ é distinguível, então dois estados $p$ e $q \in P_{i}$ são ditos equivalentes se e somente se para qualquer letra $a \in A$ a igualdade $q . a=p \cdot a$ é válida. Um algoritmo simples de minimização é definido a partir dessa propriedade: primeiro criam-se as partições pelo peso, o que pode ser realizado por uma função de $O(|\delta|)$. Segue o algoritmo geral de Revuz: 


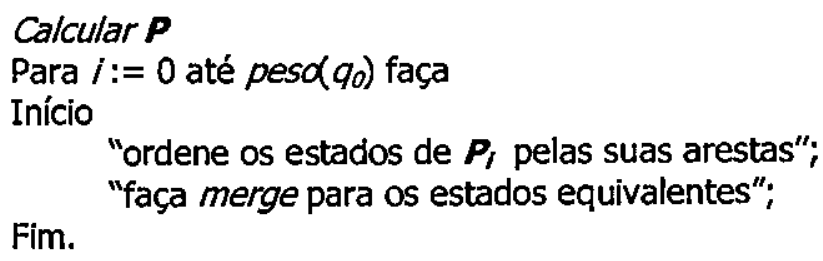

O ponto crítico deste algoritmo é a rotina de ordenação dos estados, uma vez que o particionamento ocorre apenas uma vez e pode ser realizado em tempo linear no número de transições. Assim, dado um esquema de ordenação de tempo $O(f(n))$, o algoritmo é capaz de minimizar um autômato finito acíclico em tempo $O\left(|\delta|+\Sigma f\left(\left|P_{\|}\right|\right)\right)$.

\subsubsection{O Algoritmo de Ordenação}

A implementação do algoritmo de minimização pode se aproveitar do fato de que não é necessário ordenar os estados, mas apenas distingui-los dois a dois. A ordenação lexicográfica que será descrita baseia-se neste fato, e é composta basicamente de repetidas bucket sorts.

\section{Bucket Sort}

Ordena-se uma seqüência $a_{1}, a_{2}, \ldots, a_{n}$ de inteiros $\left(1 \leq a_{i} \leq m\right)$ da seguinte forma:

(1) Cria-se um vetor de filas vazias: Queue[1..m]

(2) Rastreia-se a sequiência $a_{1}, a_{2}, \ldots, a_{n}$ colocando o elemento $a_{i}$ em $Q u e u e\left[a_{i}\right]$

(3) Concatenam-se as filas de Queue para se obter a sequência ordenada.

A complexidade de tempo é $O(n+m)$, e o espaço necessário é $O(n+m)$.

\section{Ordenação Lexicográfica}

Ordena-se uma seqüência $A_{l}, A_{2}, \ldots, A_{n}$ de $k$-uplas $\left(a_{l 1}, a_{i 2}, \ldots, a_{i k}\right)$, onde $a_{i j}$ está na faixa de 1 a $m$. Primeiramente aplica-se bucket sort à seqüência baseado no $k$-ésimo inteiro de cada $k$ upla. A nova sequiência, uma permutação da primeira, está então ordenada de acordo com o $k$ ésimo inteiro. A próxima ordenação, no ( $k$-1)-ésimo inteiro, parte dessa ordem. Então, por indução, a sequiência final, após a execução de $k$ bucket sorts, é uma permutação ordenada da sequiência inicial. A complexidade de tempo é $O(k \times(n+m))$, e o espaço necessário é $O(n+m)$. 
A generalização para sequiências de palavras de tamanhos variáveis, na faixa de 1 a $L_{\max }$, é feita aplicando-se bucket sort à palavra pelo seu comprimento e então executando a ordenação lexicográfica como descrito, com a ação adicional de concatenar as palavras de comprimento $L$ ao início da sequiência antes do $\left(L_{\max }-L\right)$-ésimo bucket sort (estas palavras estão ordenadas pela inexistência de uma $(L+1)$-ésima letra) [REV92]. Dominique Revuz descreve em seu artigo um algoritmo completo para a ordenação lexicográfica.

\subsection{Outros Trabalhos Relacionados}

Aqui serão citados outros trabalhos existentes sobre o uso de autômato finito para representação de léxicos e dicionários.

\subsection{1. "The World's Fastest Scrabble Program"}

Em 1988, Andrew Appel, um professor assistente da Universidade de Princeton, publicou um artigo na Communication of the ACM intitulado "The World's Fastest Scrabble Program" [APP88], que descreve as estruturas de dados, estratégias de busca, e heurísticas especiais que produzem um programa extremamente rápido para jogar $S c r a b b l e^{5}$. Tal rapidez é obtida pela construção de uma Trie [LAN96] e depois de um DAWG (Directed Acyclic Word Graph, uma forma de autômato finito determinístico acíclico) para armazenar o léxico.

Este artigo é um dos primeiros trabalhos publicados sobre representação de léxicos usando autômatos.

\subsection{2. "Verifica" - Uma Ferramenta de Auxílio à Redação}

Dissertação de mestrado de Hellen Pacheco (DCC-UFMG), sobre o uso de autômato finito para implementação de um verificador ortográfico, chamado Verifica, baseia-se em parte nos trabalhos de K.L.S. (seção 0, página 16) e Revuz (seção 4.2, página 23).

“O sistema testa a ocorrência das palavras da entrada em um vocabulário da Língua Portuguesa armazenado em um autômato finito determinístico acíclico. (...) Visto que um

\footnotetext{
${ }^{5}$ Um jogo no qual palavras são formadas por letras em padrões semelhantes a um jogo de palavras cruzadas.
} 
verificador ortográfico tradicional apresenta deficiências, foi estudada uma forma de se refinar a análise ortográfica a partir da análise da estrutura da frase. Foi implementado, então, um algoritmo que atribui classes sintáticas às palavras da língua. Esse é o primeiro componente de um analisador sintático para o português segundo uma nova abordagem, a abordagem funcional, que é independente de um léxico." [PAC96]

O sistema Verifica pode ser executado pela linhạ de comando, através de uma interface gráfica (criada em $T c l-T k$ ), ou ainda por meio de uma interface on-line disponível pela WWW (http: //www.dcc.ufmg.br/verifica).

\subsubsection{AUMAC/NILC}

Projeto de graduação desenvolvido por este aluno como parte dos créditos necessários para obtenção do título de Bacharel em Ciência da Computação, em 1997; foi baseado nos trabalhos de K.L.S. (seção 0, página 16) e Revuz (seção 4.2, página 23), e descreve a implementação de um protótipo para representação de um léxico simples (apenas uma lista de palavras, sem atributos) usando autômato finito. O sistema implementado neste trabalho, chamado $A U M A C / N I L C$, foi implementado em $\mathrm{C}++$ ANSI e divide-se em 2 módulos básicos:

\section{O Módulo Gerador}

Responsável pela criação e compactação do autômato. Necessita de bastante recurso computacional (disco, memória e processamento), e é executado apenas uma vez.

\section{O Módulo de Consulta}

Responsável pela utilização do autômato compactado. Os requisitos computacionais são mínimos, possibilitando seu uso eficiente em praticamente qualquer sistema.

Apesar do protótipo desenvolvido ser bastante rudimentar, os testes iniciais comprovaram a eficiência do método utilizado. 


\section{Considerações sobre os Vocabulários}

A fim de que o processo de "compactação" do autômato seja mais eficiente, deve-se otimizar também o vocabulário de entrada. Estando essa lista de palavras ordenada, alguns algoritmos podem ser simplificados, mas apenas isto não basta.

É necessário definir quantos e quais serão os símbolos distintos antes da formação do autômato. Os símbolos podem ser representados utilizando-se códigos de Huffman [LAN96], ou símbolos pouco utilizados podem ser representados como uma combinação de 2 ou mais outros símbolos. Percebe-se assim que uma boa análise do vocabulário a ser representado é essencial.

Os acentos também podem ser tratados de forma especial. Optando-se por uma representação alternativa das palavras acentuadas, pode-se aumentar a taxa de minimização do autômato. Uma dessas alternativas pode ser codificar os acentos no final da palavra, com um esquema semelhante ao mostrado na Tabela 7. Nessa proposta, os acentos são identificados por um conjunto de duplas (posição, tipo), onde posição representa a posição da letra acentuada (da direita para a esquerda), e tipo representa código do acento, conforme a Tabela 8.

Tabela 7 - Esquema de Codificação de Acentos

\begin{tabular}{|c|c|}
\hline Tipo de acento & Código \\
\hline Agudo & $\mathrm{a}$ \\
\hline Grave (crase) & $\mathrm{g}$ \\
\hline Til & $\mathrm{t}$ \\
\hline Trema & $\mathrm{u}$ \\
\hline Circunflexo & $\mathrm{c}$ \\
\hline
\end{tabular}

Com a codificação percebe-se que houve uma taxa maior de reutilização dos prefixos (demonstrado em itálico no exemplo mostrado na Tabela 8). Este tipo de código pode ser bastante útil no caso das flexões verbais, visto que cada verbo do português apresenta 51 flexões distintas e a remoção dos acentos pode fazer com que todos utilizem um prefixo comum. O esquema de codificação dos acentos ao final da palavra não chega a causar uma sobrecarga no autômato, pois os estados que representam os acentos também serão reutilizados, o que significa que palavras com igual codificação de acentos terão seus estados finais compartilhados (como mostrado em negrito nas palavras dormirá e sabiá do exemplo). 
Este tipo de otimização pode ser feito fora do sistema de criação e minimização do autômato, através da aplicação de um filtro de conversão na entrada de dados do sistema.

Tabela 8 - Exemplo de Codificação dos Acentos ao Final da Palavra

\begin{tabular}{|l|l|}
\hline Palavra normal & \multicolumn{1}{|c|}{ palavra codificada } \\
\hline dormira & dormira\# \\
\hline dormíamos & dormiamos!5a\# \\
\hline dormirá & dormira!1a\# \\
\hline sabiá & sabia!1a\# \\
\hline orgão & orgao!5a2t\# \\
\hline orgânico & organico!5c\# \\
\hline maçãa & maca!2c1t\# \\
\hline qüinqüielíngüe & quinquelingue!Cu8u5a2u\# \\
\hline
\end{tabular}

\section{O Módulo Gerador}

Este é o módulo principal do sistema, e responsável pela criação, minimização e representação do autômato. Ele necessita de uma máquina de alto desemplenho e bastante memória para ser executado, uma vez que ele instancia toda a estrutura da árvore do autômato em memória principal antes de executar o processo de minimização. É formado por 3 unidades básicas:

- AUTOMATA - contém a estrutura do autômato, e é responsável pelo processamento e inserção das palavras na estrutura.

- MINIMIZER - unidade responsável pela minimização da estrutura AUTOMATA.

- VECTOR - unidade responsável pela criação de uma estrutura linear vetorial representante do autômato da estrutura AUTOMATA.

\footnotetext{
${ }^{6}$ Neste esquema de representação, optou-se por codificar a cedilha com o código ' $c$ ', o mesmo utilizado para os acentos circunflexos, sem implicar em nenhuma confusão.
} 


\section{O Módulo de Consulta}

Este é o módulo que faz a interface entre o autômato binário e o aplicativo, sendo responsável por carregar a estrutura do autômato para a memória e executar as pesquisas. Basicamente este módulo consiste na implementação do algoritmo abaixo:

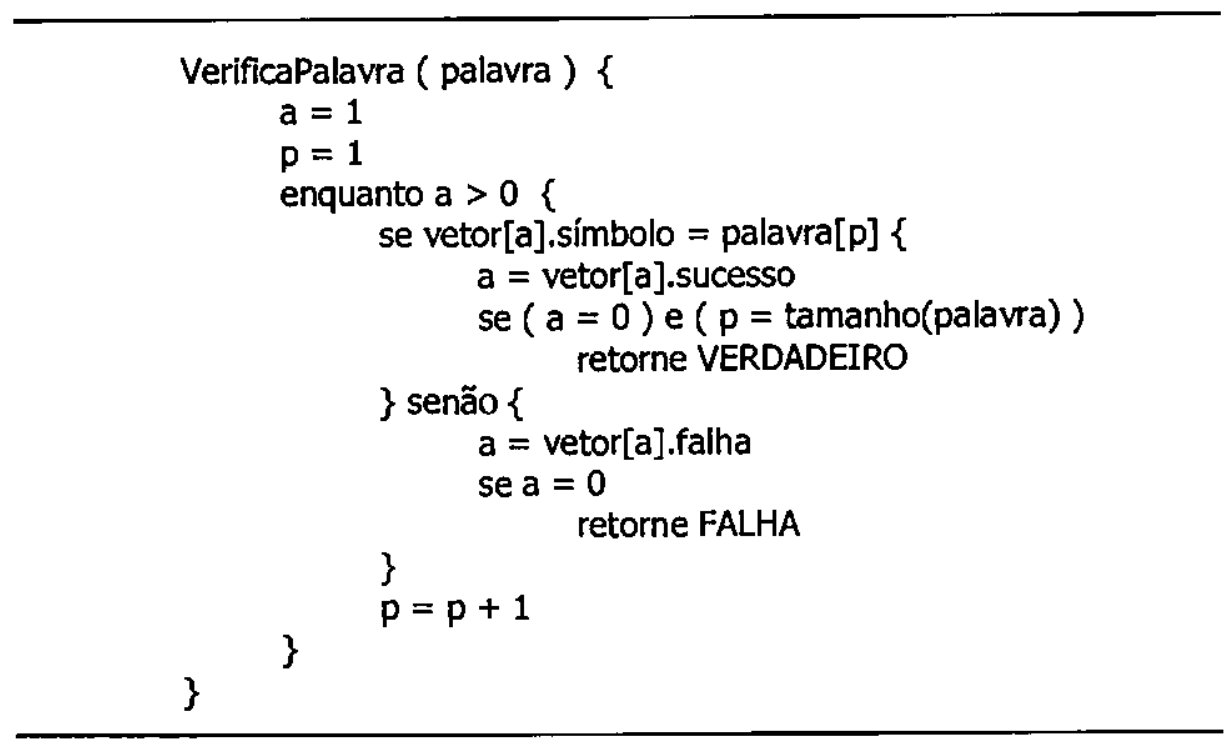

O módulo de consulta pode ser escrito com extensões específicas para cada aplicação. Para um corretor ortográfico, por exemplo, não bastaria apenas a informação sobre se uma palavra é ou não reconhecida pelo autômato, pois caso ela não seja reconhecida, algumas sugestões devem ser dadas com base nas transições válidas do autômato.

\section{Testes}

Foram realizados alguns testes com o protótipo desenvolvido. Para estes testes foi utilizado um subconjunto do vocabulário da língua portuguesa ${ }^{7}$. Serão apresentados a seguir dois dos testes realizados.

Para o primeiro teste foi utilizado um vocabulário de 5.000 palavras da língua portuguesa ${ }^{8}, \mathrm{e}$ o protótipo apresentou os seguintes resultados:

\footnotetext{
${ }^{7}$ Apesar do trabalho ter sido enfocado na representacão de vocabulários da Língua Portuguesa, o sistema implementado pode trabalhar com vocabulários de quaisquer língua.

${ }^{8} \mathrm{O}$ vocabulário consistiu das primeiras 5000 palavras do léxico da língua portuguesa desenvolvido pelo NILC.
} 


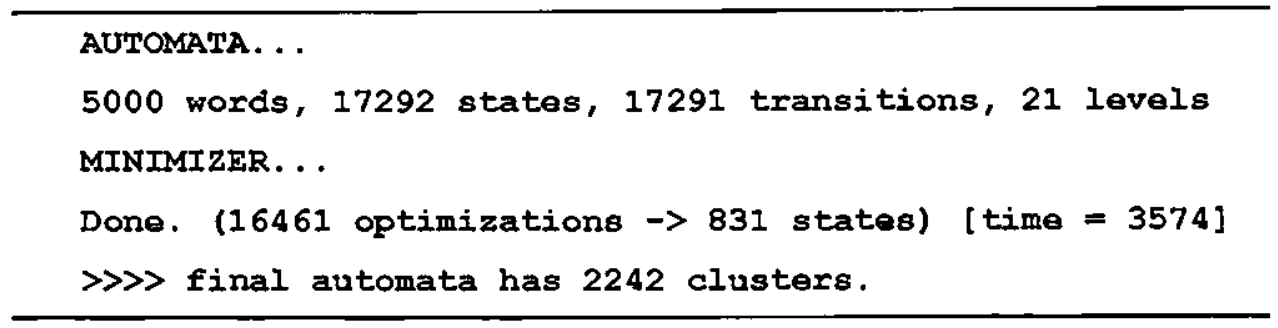

Pelo teste, que levou menos de 4 segundos para ser executado, percebe-se a enorme redução do número de transições (de 17.292 para 831 , redução de cerca de $95 \%$ ). O vetor final de representação ficou com apenas 2.242 elementos (11.210 bytes, segundo a forma de representação não otimizada utilizada pelo protótipo ${ }^{9}$ ), o que representa uma compactação de aproximadamente $80 \%$ em relação ao arquivo de entrada ( 54.634 bytes).

O outro teste foi realizado com as primeiras 1000 palavras do teste anterior:

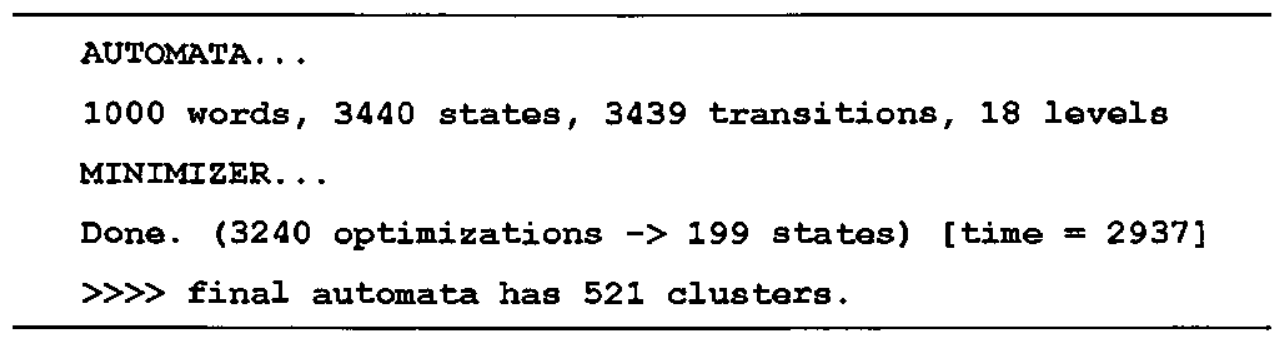

Neste teste, com $20 \%$ das palavras do exemplo anterior, a redução no número de estados foi de cerca de $95 \%$, e o vetor final ocupou 2.605 bytes (o arquivo original ocupava 11.025 bytes, portanto a "compactação" foi de $77 \%$ ).

\subsubsection{INTEX}

O INTEX é um ambiente de desenvolvimento lingüístico desenvolvido por Max Silberztein (LADL, Jussieu-FR) que permite aos usuários construírem AFs descrevendo extensas linguagens e aplicá-los a grandes textos (dezenas de milhões de palavras) em tempo real. Uma

\footnotetext{
${ }^{9}$ No protótipo são gastos 5 bytes para representar cada elemento do vetor.
} 
característica importante do INTEX é que textos, dicionários e gramáticas são todos representadas por Finite State Transducers (FSTs).

Desenvolvido desde 1992, sua atual versão (4.0) é capaz de rodar em máquinas Windows (95/NT). Mais de 30 centros de pesquisa usam o INTEX como ferramenta para pesquisa em várias áreas (lingǘśstica computacional, terminologia, análise de corpus, recuperação de informações, etc).

Maiores informações sobre o sistema podem ser obtidas no site do LADL: http://www.ladl.jussieu.fr. 


\section{Um Sistema de Representação de Grandes AF Determinísticos Acíclicos}

O sistema proposto basicamente recebe um conjunto de palavras como entrada, processaas e cria um arquivo de saída que contém uma representação otimizada do autômato gerado (Figura 8). Seu objetivo é ser simples de usar e, ao mesmo tempo, altamente extensível e integrável com outras aplicações e filtros.

O comportamento é simples: as palavras do arquivo de entrada são inseridas uma a uma no autômato, até que o gasto de memória atinja um limite pré-estabelecido, ocorrendo então uma minimização. Isso se repete até que todas as palavras sejam inseridas no autômato. Após cada minimização, e também no final do processamento de todas as palavras, podem ser geradas algumas estatísticas sobre a performance do sistema.

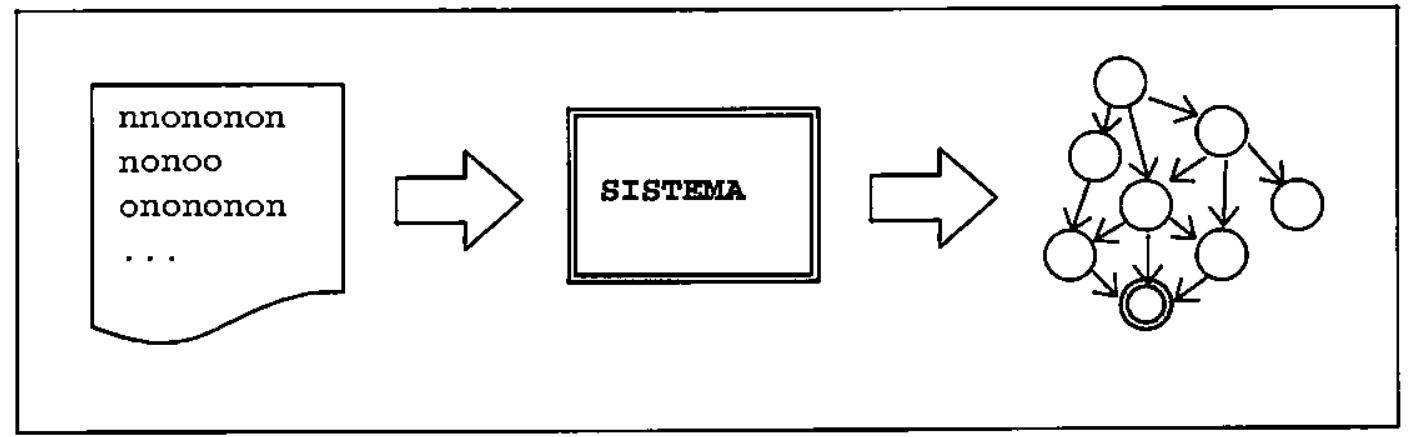

Figura 8 - Visão geral do sistema

Um protótipo foi desenvolvido em $\mathrm{C} / \mathrm{C}++$ e testes foram executados em uma estação de trabalho Sun Ultra-I, com $128 \mathrm{Mb}$ de memoria e em um PC Linux com $64 \mathrm{Mb}$ de memoria.

\subsection{Estruturas de Dados}

A estrutura de dados principal do sistema é a que representa os estados do autômato. Essa estrutura, denominada State, e as outras necessárias, são descritas a seguir:

Byte

Symbol

Triplebyte

Byte unsigned char

char

byte 0 , byte1, byte2
// Armazena um valor de 8 bits (0 a 255)

// Tipo de dado do símbolo (char, 7 bits + sinal)

// Armazena um valor de 24 bits ( 0 a 16.777.215) 


\begin{tabular}{|c|c|c|}
\hline \multicolumn{3}{|r|}{ ( } \\
\hline Byte & flags & // Flags para estado terminal, visitado, proper, etc \\
\hline TripleByte & id & // Identificador único do estado \\
\hline Byte & height & // Altura do estado \\
\hline State* & level_next, & level_prev // Ponteiros para os estados vizinhos de nível \\
\hline Transition* & trans & // Transições do estado \\
\hline BinTree* & ref & // Estados que trazem à esse estado \\
\hline \multicolumn{3}{|l|}{ Transition } \\
\hline Symbol & symbol & // Símbolo associado à transição \\
\hline State* & destination & //Estado para onde a transição leva \\
\hline Transition* & next & // Ponteiro para a próxima transição do estado \\
\hline \multicolumn{3}{|l|}{ BinTree } \\
\hline Word & key & // Chave para o no \\
\hline State* & state & // Dado do nó da árvore binária \\
\hline BinTree* & left, right & // Sub-árvores da esquerda e direita \\
\hline
\end{tabular}

A estrutura State ocupa apenas 21 bytes $^{10}$, cada Transition ocupa 9 bytes, e cada BinTree 14 bytes. Como cada nova Transition leva à criação de um novo nó BinTree, temos que cada transição do autômato implica em um gasto de 23 bytes $(9+14)$. Isso nos leva à seguinte fórmula de uso de memória ${ }^{11}$, onde $s$ representa o número de estados do autômato, e $t$ o número de transições:

$$
m=21 s+23 t
$$

Como o sistema foi desenvolvido de forma a permitir que as minimizações ocorram de forma intercalada com as inserções, ele pode rodar em estações de menor capacidade de memória, mesmo para grandes conjuntos de dados.

A estrutura de dados que representa o autômato é a Automata. Ela e as outras estruturas associadas são descritas a seguir:

\section{List}

\begin{tabular}{|c|c|c|}
\hline & state & // Referência para oEstado \\
\hline
\end{tabular}

Hash

List* head[65536], tail [65536] // Itens da tabela hash (head/tail de cada lista)

\footnotetext{
${ }^{10}$ Considerando que cada ponteiro ocupa 32 bits ( 4 bytes), o que acontece na maioria das plataformas atuais.

"A fórmula leva em consideração que os dados serão alinhados byte a byte em memória, sem otimizações de acesso geralmente feitas pelo compilador, e sem overheads nas estruturas alocadas pelo sistema.
} 


\section{Automata}

$\begin{array}{lll}\text { State* } & \text { start } & \text { //Estado inicial do autômato } \\ \text { State* } & \text { level }[256] & \text { //Vetor das listas de níveis } \\ \text { Hash } & \text { hash } & \text { // Tabela hash usada na minimização } \\ \text { int } & \text { n_states } & \text { // Número de estados do autômato } \\ \text { int } & \text { n_trans } & \text { // Número de transições do autômato } \\ \text { int } & \text { n_words } & \text { //Número de palavras inseridas } \\ \text { int } & \text { n_minimize } & \text { // Número de minimizações efetuadas }\end{array}$

A estrutura Automata ocupa pouco mais que $500 \mathrm{~Kb}$ de memória. O grande tamanho se deve à tabela hash embutida. Durante a fase de minimização, essa tabela é preenchida para cada diferente nível do autômato, criando listas temporárias. Cada nó da lista ocupa 12 bytes, e existirão no máximo $w$ nós em cada fase da minimização (onde $w$ é o número de palavras já inseridas no autômato), no pior caso. Assim, um conjunto de 1.000 .000 de palavras criará uma estrutura temporária de, no máximo, $12 \mathrm{Mb}$ (em condições ideais de gasto de memória).

Por fim, a estrutura final de representação do autômato (na verdade representa apenas as suas transições), é a Vector. Essa estrutura é a representação mais compacta criada pelo sistema, e é ela que será utilizada nas posteriores aplicações.

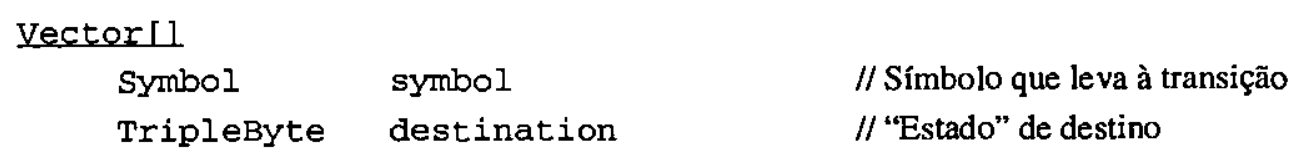

A estrutura Vector é criada somente após todas as palavras terem sido inseridas no autômato, e este já tiver sido minimizado. Cada estado do autômato é "desmembrado" em suas transições, e estas representadas sequiencialmente na estrutura Vector. O bit mais significativo do destination é usado para marcar a última transição de cada estado.

O tamanho final, em bytes, dessa representação do autômato é de 4 vezes o número de transições. Um sistema de compactação externo, como o gzip, pode ser usado para compactar essa estrutura, mas quando ela for usada pela aplicação ela deverá ser descompactada. Mesmo assim essa abordagem é interessante, por exemplo, no caso de uma aplicação Web que tem que fazer o download de seu dicionário. 


\subsection{Algoritmos Propostos}

Os principais algoritmos envolvidos no sistema são: inserção de uma nova palavra, minimização do autômato e criação da representação final. Os algoritmos serão expostos no formato de pseudocódigo, a começar pelo de inserção (Figura 9).

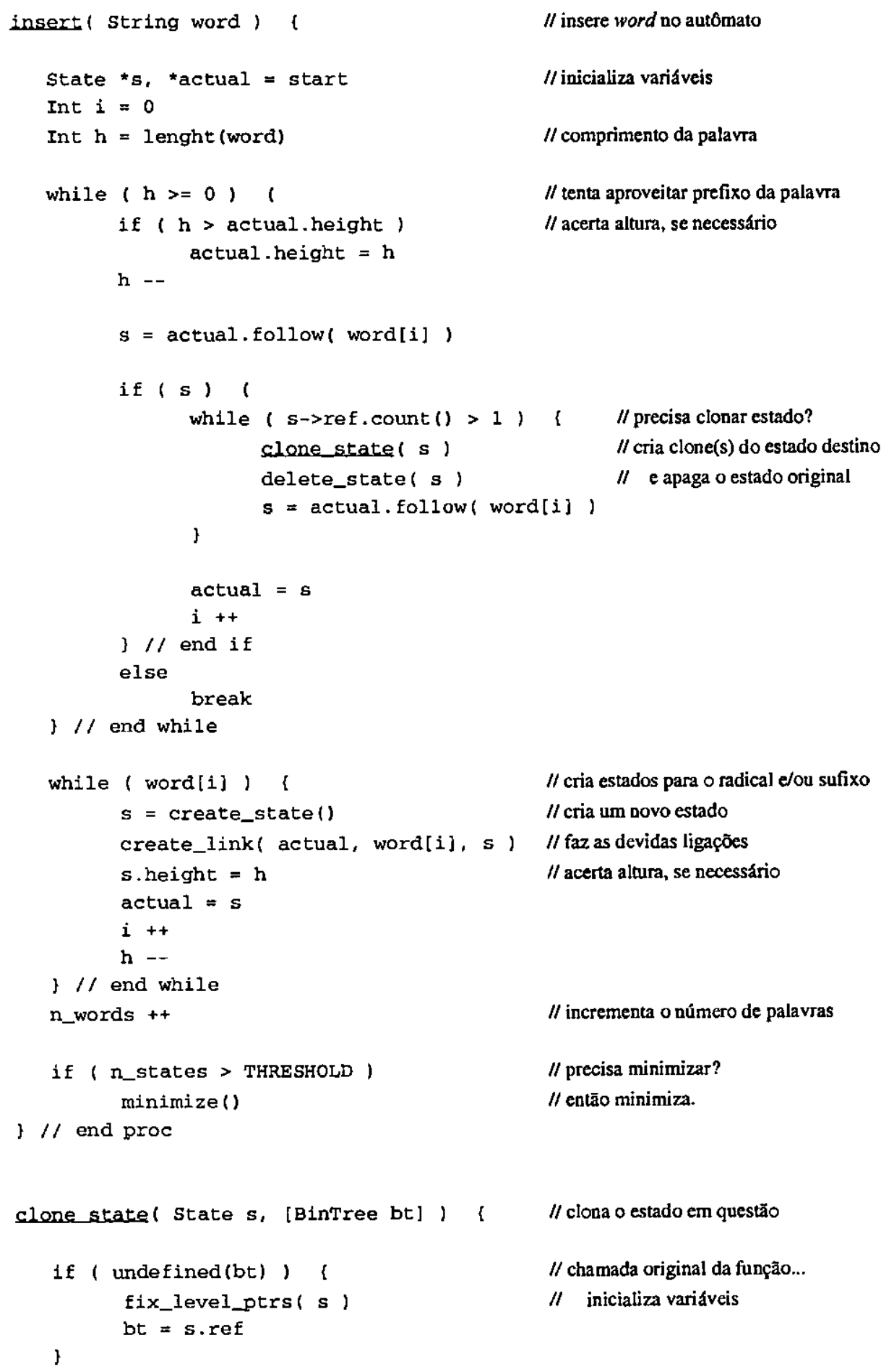




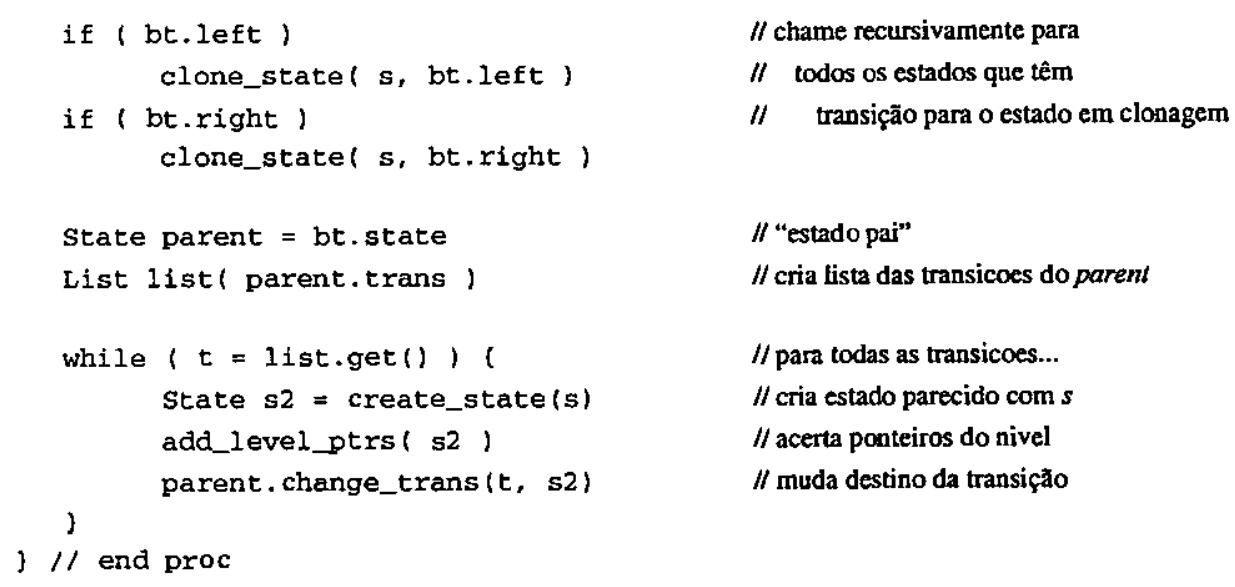

// chame recursivamente para

// todos os estados que têm

// transição para o estado em clonagem

// "estado par"

// cria lista das transicoes do parent

// para todas as transicoes...

// cria estado parecido com $s$

// acerta ponteiros do nivel

// muda destino da transiçăo

\section{Figura 9 - Processo de inserçăo de uma palavra no autơmato}

A função de inserção inicialmente verifica quanto do prefixo da palavra pode ser reutilizado na atual estrutura do autômato. Depois, o restante das letras da palavra será representado através de novos estados e transições que serão criadas. Caso o estado que liga o prefixo reutilizado e o restante da palavra seja destino de mais de uma transição, então uma operação de clonagem é necessária. Isso é necessário para se manter o autômato determinístico e não permitir o reconhecimento de palavras inválidas. Assim, a função clone_state faz com que esse estado passe a ser destino de apenas uma transição, como mostra a Figura 10. Essa operação consiste basicamente na criação de novos estados e redirecionamento de transições.

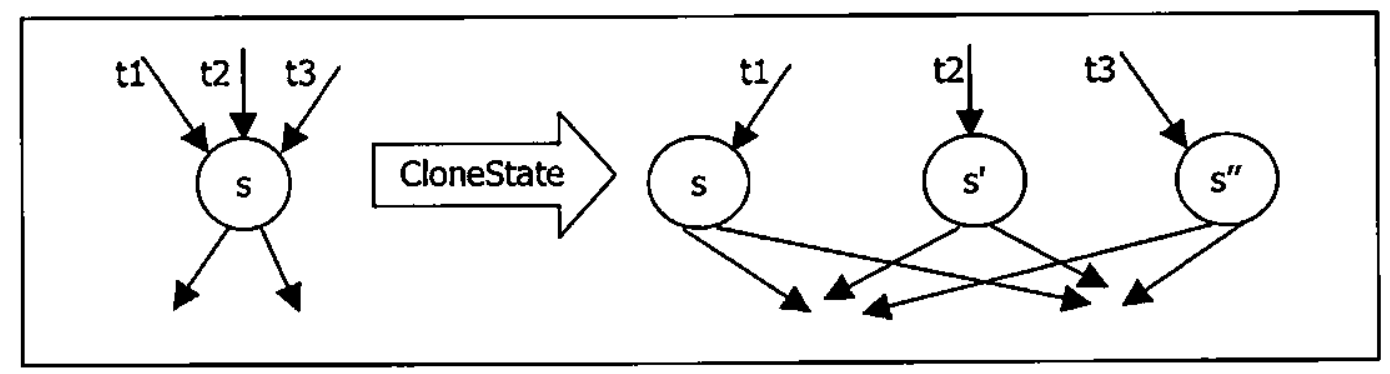

Figura 10 - Operação de clonagem de estado

O segundo algoritmo, o mais importante de todos, é o responsável pela minimização do autômato (Figura 11). Ele é uma adaptação do algoritmo de Revuz descrito anteriormente. A diferença é que ao invés de uma função de ordenação, é utilizada uma estrutura hash para identificação dos estados equivalentes.

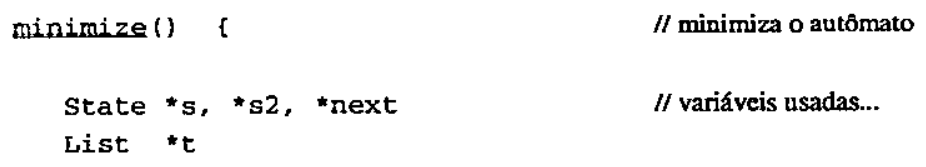




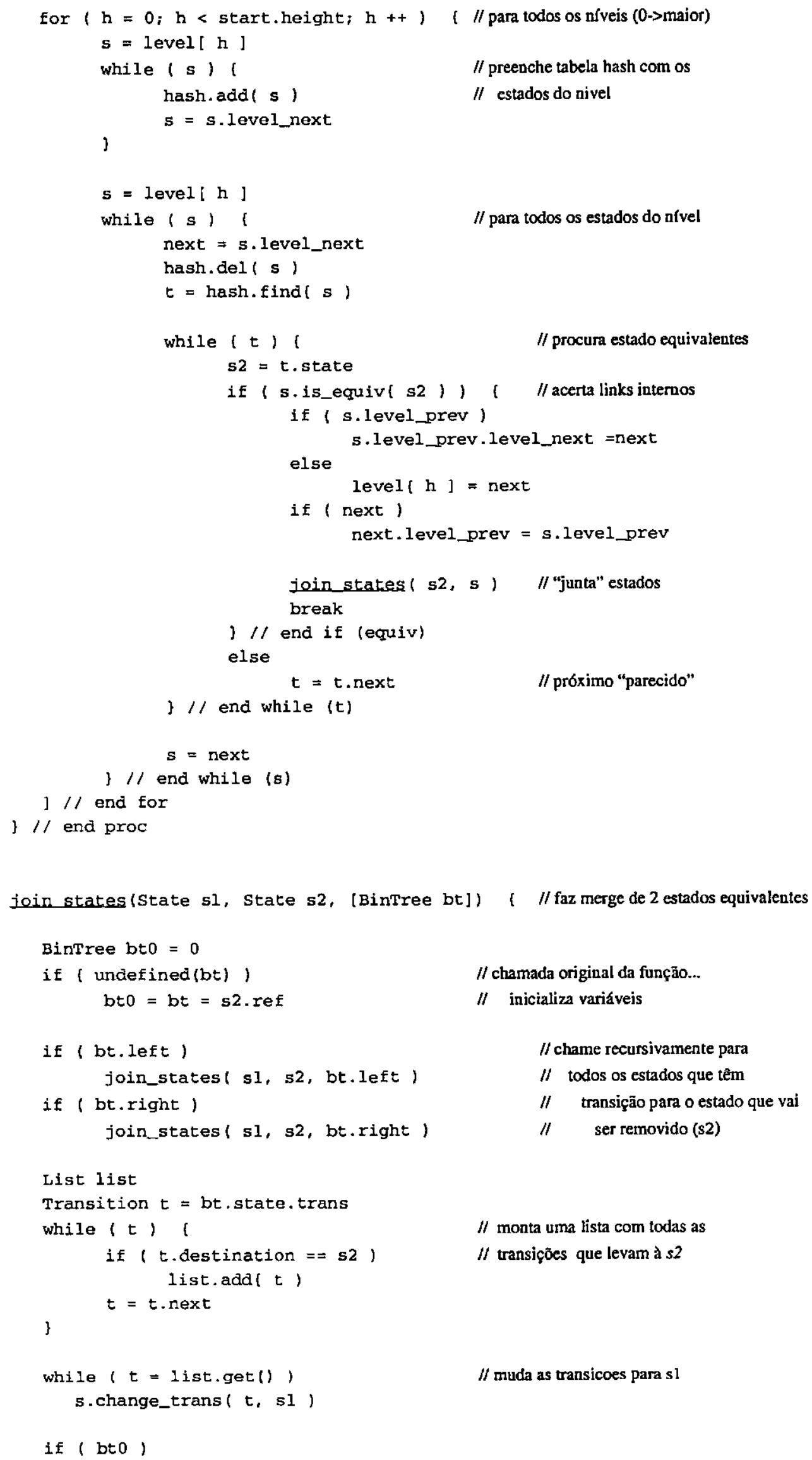

// chamada original da função... // inicializa variáveis 


\section{Figura 11 - Processo de minimização do autômato}

O processo de minimização ocorre desde o último nível do autômato, "subindo" até o estado inicial. Para cada nível, são detectados os estados que são equivalentes e esses são "mesclados". Para distinguir os estados equivalentes, é utilizada uma tabela hash que permite a rápida escolha de estados "semelhantes". A função hash é baseada no id do estado e nas suas transições, e resulta em um valor de 16 bits (65536 possibilidades).

A função mais importante usada na minimização é a join_state, responsável pela real redução do número de estados e transições do autômato. Após se determinar que dois estados são equivalentes, esses dois estados podem ser representados por apenas um deles, sem "danos" ao autômato. É isso o que faz a função join_state $(s 1, s 2)$ : todas as transições que levavam à $s 2$ são redirecionadas para $s 1$, e o estado $s 2$ e suas transições são removidos (conforme visto na Figura 5 , página 10)

Por fim, o terceiro algoritmo usado é o que cria a representação física vetorial do autômato (Figura 12).

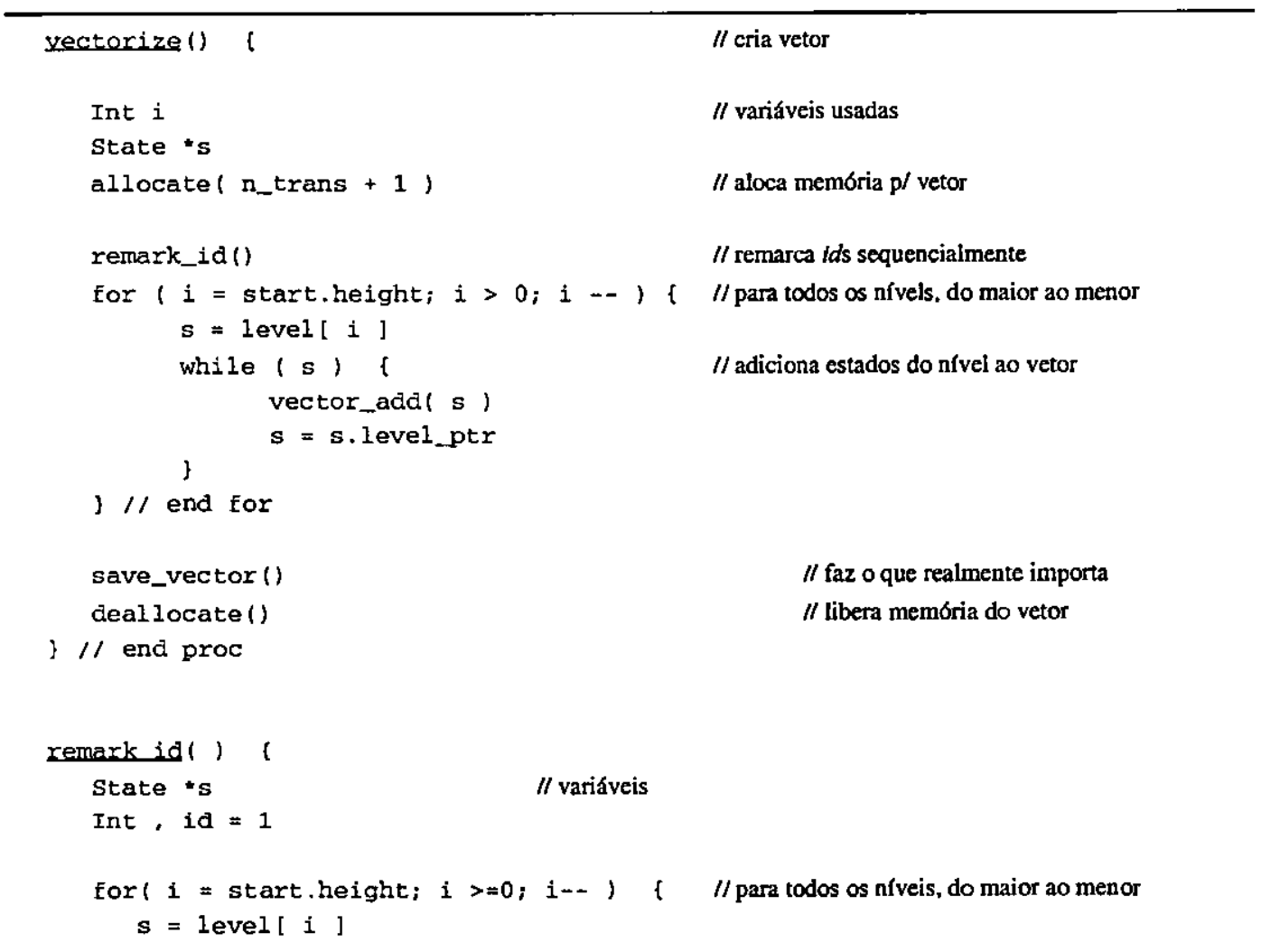




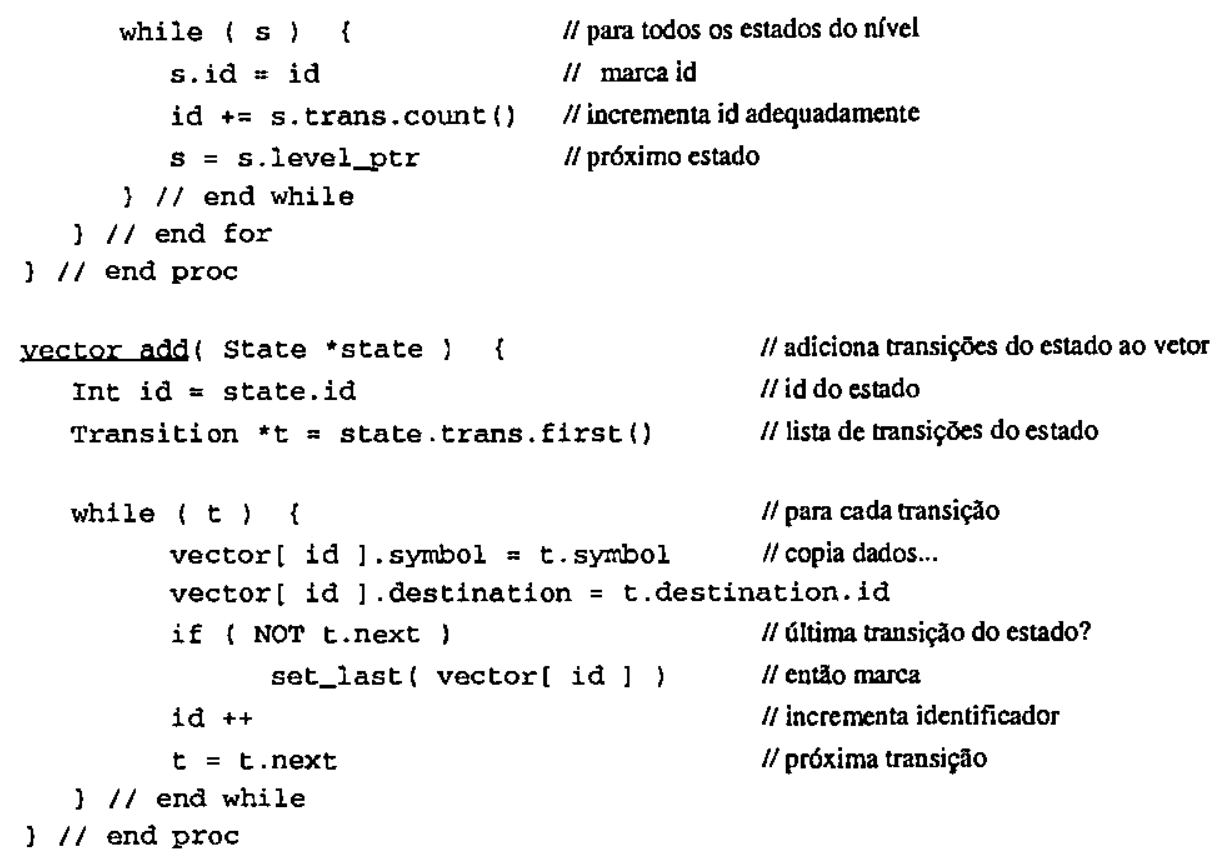

Figura 12 - Processo de criaçăo da representaçao final do autômato

O algoritmo, através da função remark_id 0 , modifica o valor do campo id dos estados, para que esses se tornem seqüenciais (uma vez que no processo de minimização são gerados vários "buracos"). Após essa remarcação, a função simplesmente preenche o vetor.

\section{ALGORITMO DE BUSCA NO VETOR}

A aplicação final, como foi dito anteriormente, utilizará apenas a representação vetorial gerada no final da fase de conversão do léxico. O algoritmo para verificar a presença de uma palavra no autômato é bastante simples, e deve ser modificado de acordo com necessidades da aplicação (como obtenção de palavras semelhantes, por exemplo). Segue o pseudo-código:

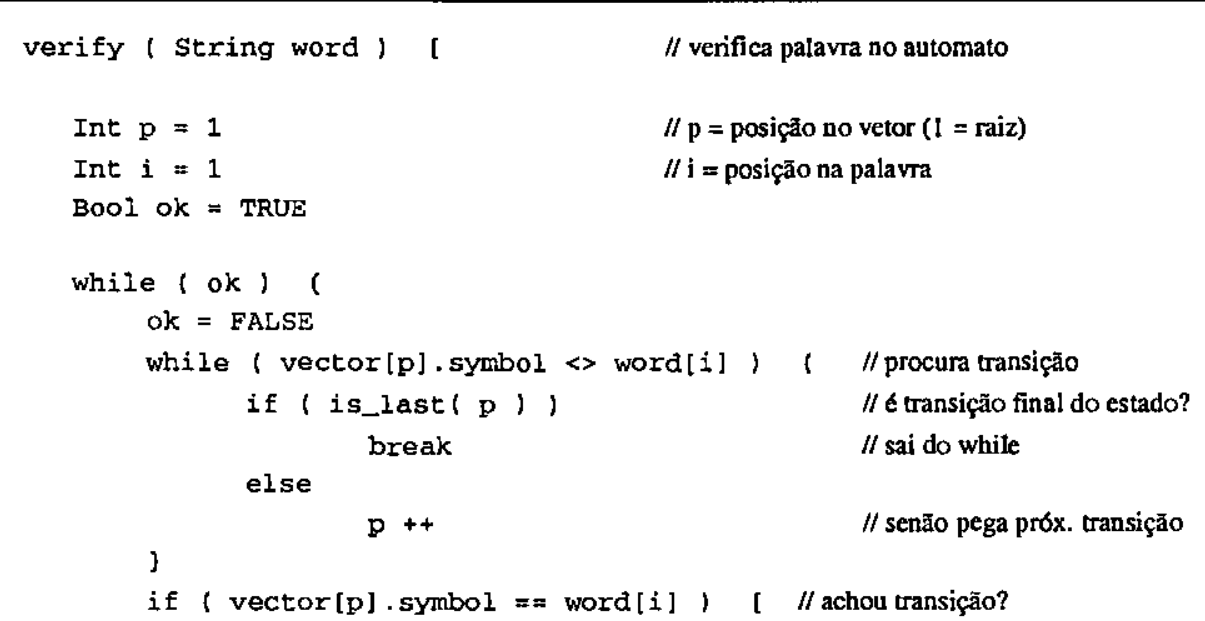




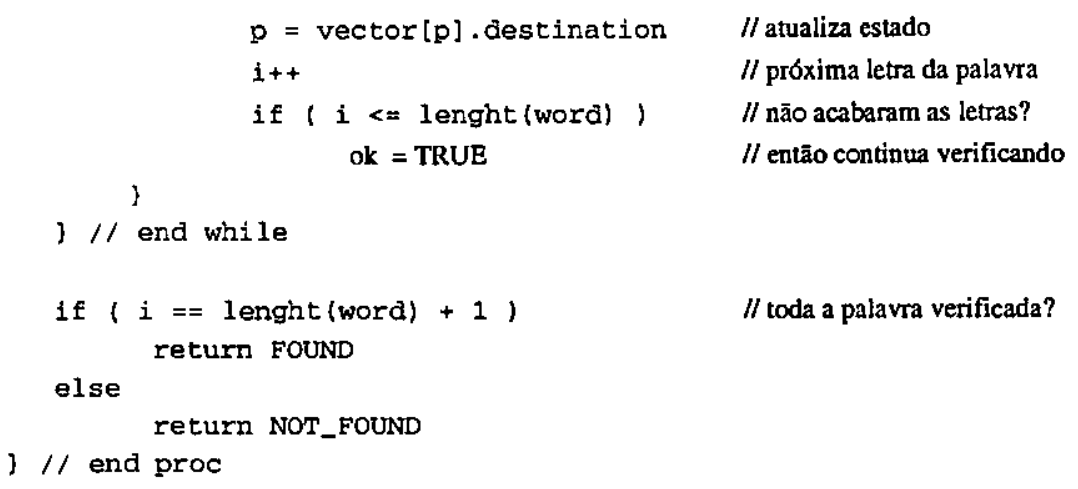

Figura 13 - Processo de busca de uma palavra na estrutura final

\subsection{Resultados}

Como foi dito, um protótipo foi desenvolvido em paralelo com a definição dos algoritmos. Esse protótipo mostrou-se eficaz no tratamento em tempo-real de léxicos com centenas de milhares de entradas, rodando em workstations relativamente simples ${ }^{12}$. Na Tabela 9 são apresentados os resultados de testes envolvendo léxicos simples (contendo apenas palavras, sem nenhum atributo associado).

O léxico do português utilizado foi obtido a partir do léxico do NILC (seção 2.2), de onde foram extraídas apenas as palavras, e descartadas as que continham hífens (para excluir as ênclises e mesóclises a fim de simplificar o processo). Os outros léxicos foram obtidos em ftp://ftp.uu.net/doc/dictionaries.

Para efeito de armazenamento ou transferência por rede de comunicação, por exemplo, o formato compactado do autômato (como sugerido na última coluna da tabela superior) é totalmente aceitável. Entretanto, para uso do autômato ele deve ser descompactado, de forma que o requisito de memória real é o descrito na quarta coluna da mesma tabela.

\footnotetext{
${ }^{12}$ Foram utilizados nos testes um Pentium 166MHz rodando Linux (kernel 2.2.5-15 + glibc 2.1.1) com 64Mb de memória RAM; e uma Sparc Station Ultra-I rodando Solaris 2.5 .1 , com $128 \mathrm{Mb}$ de RAM.
} 
Tabela 9 - Dados sobre os léxicos usados nos testes

\begin{tabular}{|c|c|c|c|c|c|}
\hline Léxico & No. Palavras & Tamanho & Tam. Autômato & Aut. Compactado $^{13}$ & Reduçãa $^{\text {14 }}$ \\
\hline Sueco & 14.944 & $123 \mathrm{~Kb}$ & $100 \mathrm{~Kb}$ & $65 \mathrm{~Kb}$ & $47 \%$ \\
\hline Inglês & 45.402 & $399 \mathrm{~Kb}$ & $198 \mathrm{~Kb}$ & $126 \mathrm{~Kb}$ & $68 \%$ \\
\hline Italiano & 61.183 & $560 \mathrm{~Kb}$ & $107 \mathrm{~Kb}$ & $58 \mathrm{~Kb}$ & $90 \%$ \\
\hline Português & 431.767 & $4.723 \mathrm{~Kb}$ & $380 \mathrm{~Kb}$ & $218 \mathrm{~Kb}$ & $95 \%$ \\
\hline
\end{tabular}

\begin{tabular}{|c|c|c|c|c|c|c|}
\hline Léxico & Tot. Estados $^{\text {15 }}$ & Estados $^{16}$ & Transiçōes $^{16}$ & Trans./Est. $^{17}$ & Tempo $^{{ }^{18}}$ & Minim. $^{19}$ \\
\hline Sueco & 59.133 & $13.269(22 \%)$ & $25.515(43 \%)$ & 1,92 & $0: 04$ & 1 \\
\hline Inglês & 160.234 & $23.102(14 \%)$ & $50.748(32 \%)$ & 2,20 & $0: 25$ & 2 \\
\hline Italiano & 176.466 & $10.311(6 \%)$ & $27.367(15 \%)$ & 2,65 & $0: 32$ & 2 \\
\hline Português & 1.272 .983 & $33.852(3 \%)$ & $97.277(8 \%)$ & 2,87 & $4: 17$ & 13 \\
\hline
\end{tabular}

A performance de cada um dos quatro léxicos varia devido às características de cada língua, mas mesmo para o primeiro léxico (sueco) o formato ainda é vantajoso. Quanto ao léxico do português a performance final foi excepcionalmente boa $(95 \%$ de redução no tamanho, $97 \%$ no número de estados e $92 \%$ no de transições), de forma que o esquema de representação sugerido se torna praticamente mandatário.

Vale lembrar que o acesso à estrutura do autômato é feito de forma direta, sendo necessárias apenas $n . m$ operações de comparação, onde $n$ é o número de letras da palavra sendo procurada, e $m$ é o número médio de transições por estado.

Finalmente, quanto ao uso de memória, o maior léxico (do português) precisou de apenas $14 \mathrm{Mb}$ de memória RAM para ser executado, o que mais uma vez demonstra o potencial do sistema em tratar léxicos de grande porte mesmo em workstations mais modestas (veja seção de considerações abaixo).

\footnotetext{
${ }^{13}$ Essa coluna representa o tamanho do arquivo representante do autômato, após ser submetido ao filtro de compactação gzip com parâmetro máximo $(-9)$ de eficiência..

14 A redução apresentada foi calculada pela razāo entre o tamanho do autômato compactado e o tamanho do arquivo original.

${ }^{15}$ Total de estados representa o número total de estados que esse autômato teria se não sofresse nenhuma minimização.

${ }^{16}$ O percentual entre parênteses representa a relação entre o número final de estados e o número total (da segunda coluna). 0 mesmo se aplica à quarta coluna, com relação ao número de transições.

${ }^{17}$ Número médio de transiçōes em cada estado do autômato.

${ }^{18}$ Tempo total expresso em minutos:segundos, gasto no processo de criação do autômato, usando um Pentium166/Linux com $55 \mathrm{Mb}$ de memoria livre e threshold de 100.000 estados.

${ }^{19}$ A coluna indica quantas operaçōes de minimizaçāo foram necessárias.
} 


\subsection{Considerações}

Algumas considerações importantes devem ser feitas quanto aos algoritmos e estruturas expostos e quanto à forma de implementação escolhida (linguagem, sistema operacional, máquina, etc).

Os elementos do sistema foram definidos de forma a modelar uma estrutura bem próxima à estrutura teórica de um autômato. Isso facilita tanto o entendimento quanto à implementação de novas funções no sistema, mas compromete um pouco a performance no que diz respeito ao espaço de armazenamento (memória RAM).

Outra questão importante é sobre o gasto teórico e o real de memória. As bibliotecas de alocação dinâmica de memória costumam não ser totalmente configuráveis pelo usuário e, em geral, não apresentam algoritmos de reutilização de memória muito eficientes, o que pode resultar em muita fragmentação na memória alocada. Isso varia para cada sistema operacional e para cada biblioteca de alocação de memória. Uma abordagem interessante é implementar um módulo responsável pelo gerenciamento de memória, que trabalharia em uma enorme área de memória pré-alocada no início do programa. Outra abordagem é reiniciar o programa periodicamente, por exemplo, a cada $n$ minimizações.

Enfim, para que o sistema possa ser capaz de tratar com léxicos de vários milhões de entradas de uma forma aceitável, as limitações físicas não devem ser ignoradas, mas sim contornadas. 


\section{Representação de Atributos Lexicais}

Neste capítulo será abordada a questão da associação de atributos lexicais, tais como gênero, número e forma canônica, às entradas do léxico. A abordagem utilizada aqui será a de embutir os atributos à entrada, de forma a centralizar o procedimento de compactação do léxico em um sistema de representação e minimização de autômatos finitos, como o descrito no capítulo anterior.

O trabalho aqui descrito usou como base o léxico do NILC (descrito na seção 2.2), cujo formato dos atributos foi alterado para representação mais eficiente no autômato. Esse formato será descrito na seção 6.2, e é baseado no estratégia usada em [KOW98] (seção 4.1.4).

\subsection{Considerações Iniciais}

A representação dos atributos lexicais deve permitir identificar as entradas de forma eficiente através de seu prefixo e embutir os possíveis atributos como sufixos dessa entrada, como no exemplificado na Figura 14.

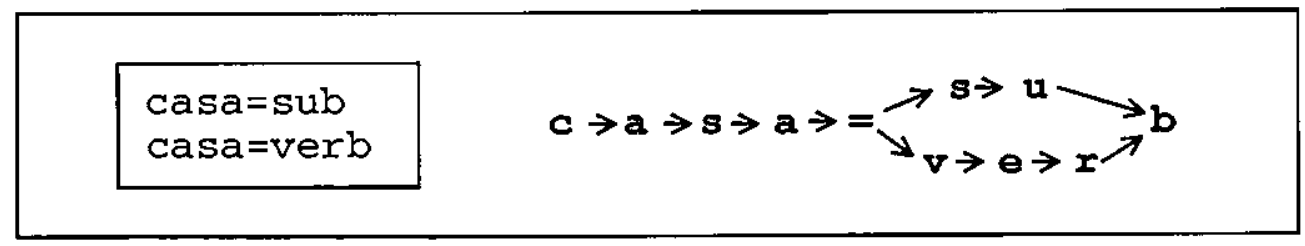

Figura 14 - Reutilização de sufixos

Nesse exemplo, dada a palavra casa, pode-se gerar recursivamente todos os possíveis sufixos, obtendo-se verbo e sub.

Por outro lado, a ordem e o formato dos atributos nas entradas devem levar em conta a capacidade do autômato de reutilização dos sufixos, de trás para frente, durante a fase de minimização. Nesse aspecto, o atributo representante da forma canônica, por exemplo, merece um tratamento especial, já que poderia comprometer a eficiência do autômato. Um formato possível é representar apenas a diferença de sufixo da palavra, como na Figura 15. 


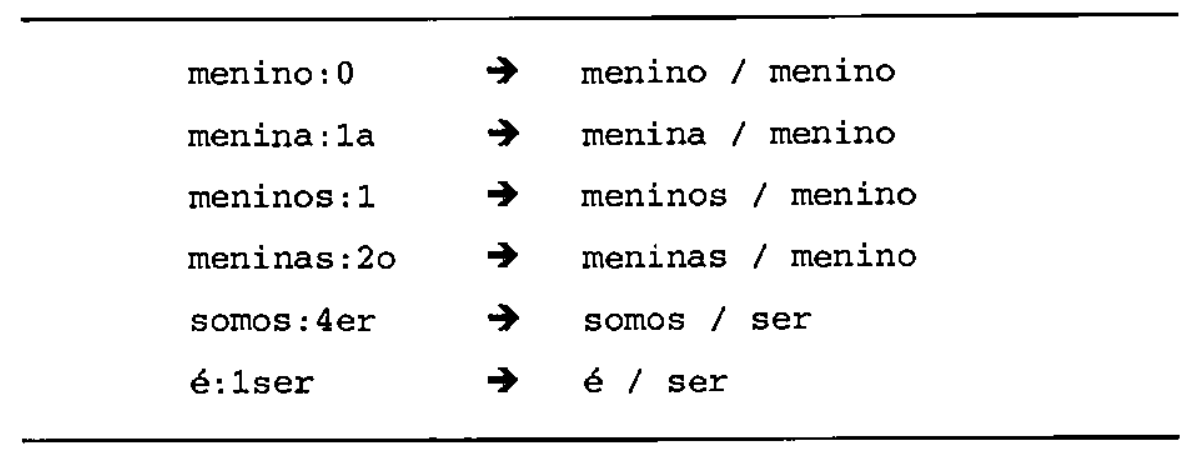

Figura 15 - Representação por diferença de sufixo

Nesse formato, o dígito indica quantos caracteres a partir do final da palavra devem ser removidos, e quais devem ser inseridos.

Finalmente, a parte mais complexa é a de se definir quais serão os valores dos atributos, e em que ordem eles vão aparecer na entrada do léxico. A resposta a essa questão depende de cada léxico, caso se queira um sistema realmente eficiente.

\subsection{Proposta de Formato para o Léxico do NILC}

Baseado no esquema de representação apresentado em [KOW98], um formato alternativo de representação do léxico do NILC será descrito nessa seção, levando-se em consideração três pontos importantes:

1. Afixos que podem ser facilmente reutilizados;

2. Fácil interpretação das entradas do léxico;

3. Formato facilmente extensível.

Foi desenvolvido um filtro para converter o léxico do formato original para o formato otimizado que está sendo proposto. O programa gera, para cada entrada do léxico do NILC, uma ou mais entradas simplificadas (já que cada entrada do léxico original pode embutir várias entradas distintas). Também é gerada uma entrada reversa para cada entrada do léxico otimizado, para permitir a busca no autômato pela forma canônica da palavra. A Tabela 10 apresenta alguns exemplos do formato proposto. 
Tabela 10 - Entradas do léxico do NILC e respectivas conversões para o léxico otimizado

\begin{tabular}{|c|c|}
\hline Léxico original & Léxico Otimizado \\
\hline $\begin{array}{l}a=\text { <ART.E.SI.DE.?.?. [0] . \#PREP.C. [] [a]0.\# } \\
\text { PRON.E.SI.[DEM.OBL-AT.]3S.?.?.C. [] [0]0.\# } \\
\text { ABREV.M.SI.[a]0.\#S.M.SI.N.[]?.?.[]0.> }\end{array}$ & $\begin{array}{l}a=10=A R T, E, S I, D E \\
0 \mid 0=A R T, M, S I, D E \\
a=0=P R E P, 0 \\
a \mid 0=P R E P, 0 \\
a=10=P R O N, E, S I, D E M, 10 \\
0 \mid 0=\text { PRON , M, SI, DEM, } 0 \\
a=10=\text { PRON , E , SI, OBL-AT, } 10 \\
0 \mid 0=\text { PRON , M, SI, OBI-AT, } 0 \\
a=0=A B R E V, 0 \\
a \mid 0=A B R E V, 0 \\
a=0=S, M, S I, N, 0 \\
a \mid 0=S, M, S I, N, 0\end{array}$ \\
\hline $\begin{array}{l}\text { ab-rogava=<V. [] [ [RRET-IMPERE.EU. } \\
\text { PRET-IMPERF. ELE.] ]. [] [ab-rogar] } 0 .>\end{array}$ & $\begin{array}{l}a b-r o g a v a=2 r=V, P R S T-I M P E R E, E U, N \\
a b-r o g a r \mid 1 v a=V, \text { PRET-IMPERF, } E U, N \\
a b-r o g a v a=2 r=V, P R E T-I M P E R E, E I E, N \\
a b-r o g a r \mid 1 v a=V, P R E T-I M P E R E, E L E, N\end{array}$ \\
\hline $\begin{array}{l}\text { enquanto=<CONJ. [COORD. [] SUBORD. } \\
\text { [PROPOR. TEMP.] ] [enquanto] } 0 .>\end{array}$ & $\begin{array}{l}\text { enquant } 0=0=\text { CONJ, SUBORD-PROPOR } \\
\text { enquan to } \mid 0=\text { CONJ, SUBORD-PROPOR } \\
\text { enquanto }=0=\text { CONJ, SUBORD-TEMP } \\
\text { enquan to } \mid 0=\text { CONJ, SUBORD-TEMP }\end{array}$ \\
\hline
\end{tabular}

As entradas que contém ' $I$ ' como primeiro separador são as entradas reversas. Para simplificar o sistema, algumas informações da entrada original estão sendo descartadas (regras de derivação e informações de regência, por exemplo).

A utilização dos tokens completos (CONJ, PRET-IMPERE, SUBORD-TEMP, etc.), ao invés de identificadores mais reduzidos, não chega a comprometer o resultado final, pois esses tokens serão altamente reutilizados no processo de minimização realizado no autômato (veja seção de resultados, logo adiante).

Testes realizados com o formato que está sendo proposto indicaram uma redução maior que $90 \%$ no número de estados/transições do autômato, ou seja, muito próximas às obtidas com o léxico simples na seção 5.3; e uma redução de tamanho maior que $90 \%$ (em relação ao tamanho da estrutura final compactada e o arquivo original), também próxima à obtida com os léxicos simples. Isso significa que o overhead gerado pelos atributos no formato otimizado sugerido foram muito bem compensados pelo mecanismo implícito de reutilização de afixos do autômato. 


\subsubsection{BNF do Formato Proposto de Léxico}

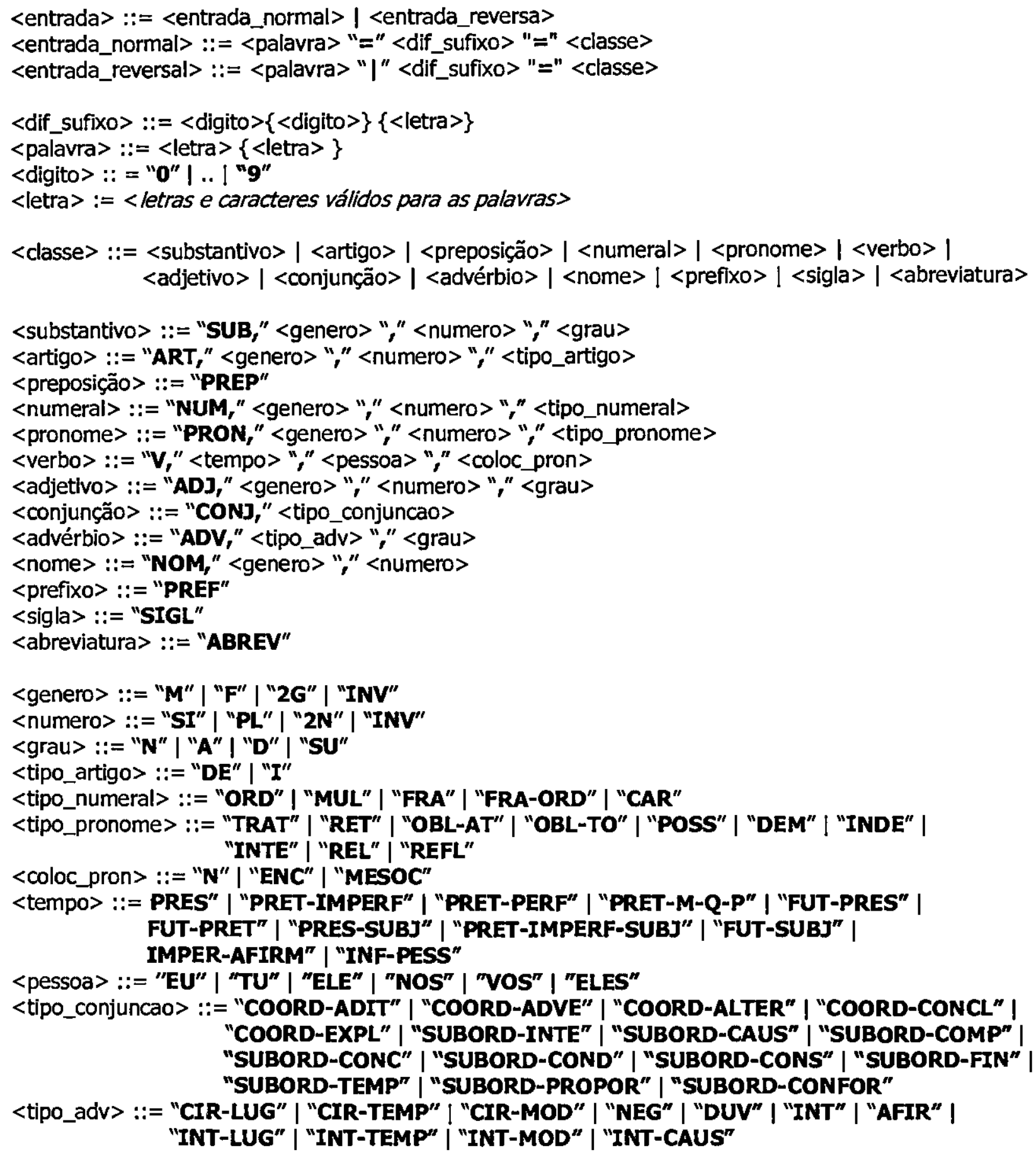

\subsection{Resultados}

Para os testes executados, foram utilizados dois subconjuntos do léxico do NILC (seção, 2.2): o primeiro, contendo cerca de $1 \%$ das entradas do léxico, e que será referenciado por LEX1 
nessa seção; e o segundo, contendo cerca de $10 \%$ das entradas do léxico, que será chamado de LEX10. Os dois léxicos foram obtidos selecionando-se linhas do arquivo original de forma randômica, de forma a se tentar gerar uma amostra representativa do léxico original. Cada léxico foi convertido para o formato otimizado apresentado, gerando quatro arquivos:

- LEX*.w -- contém apenas as palavras (distintas) do léxico

- LEX*full _- contém todas as entradas (diretas e reversas)

- LEX*.dir -- contém apenas as entradas diretas (pela palavra)

- LEX*.rev -.. contém apenas as entradas reversas (pela canônica)

Dessa forma, foram gerados 8 léxicos, conforme descrito na Tabela 11, que também inclui o léxico original (formato do NILC) como referência.

Tabela 11 - Descrição dos léxicos utilizados nos testes do formato

\begin{tabular}{|c|c|c|}
\hline Léxico & Entradas & Tamanho \\
\hline LEX1 Original & 17.110 & 1.052 .012 \\
\hline LEX1.w & 17.109 & 236.882 \\
\hline LEX1.full & 34.520 & 1.252 .546 \\
\hline LEX1.dir & 17.260 & 626.273 \\
\hline LEX1.rev & 17.260 & 626.273 \\
\hline LEX10 Original & 156.580 & 9.842 .373 \\
\hline LEX10.w & 156.532 & 2.166 .633 \\
\hline LEX10.full & 316.602 & 11.479 .906 \\
\hline LEX10.dir & 158.301 & 5.739 .953 \\
\hline LEX10.ver & 158.301 & 5.739 .953 \\
\hline
\end{tabular}

Inicialmente foram convertidos os léxicos apenas das palavras, para referência e cálculos de performance dos outros testes. Os resultados estão na Tabela 12.

Tabela 12 - Resultados da conversão das palavras de LEX1 e LEX10

\begin{tabular}{|c|c|c|c|c|c|c|}
\hline Léxico & Tot. Estados & Estados & Transiçбes & Tempo & Min. & Aut. Compact. \\
\hline LEX1.w & 134.213 & $23.784(82 \%)$ & $39.961(70 \%)$ & $0: 07$ & 3 & $101 \mathrm{~Kb}$ \\
\hline LEX10.w & 833.494 & $75.342(91 \%)$ & $180.599(78 \%)$ & $1: 59$ & 17 & $459 \mathrm{~Kb}$ \\
\hline
\end{tabular}

Na Tabela 13 são apresentados os resultados obtidos na conversão dos léxicos que foram convertidos para o formato. O maior processamento (LEX10.fulI), que durou pouco mais que 10 minutos em um Pentium166/Linux, consumiu 32Mb de memória RAM. 
Tabela 13 - Resultados de LEX1 e LEX10

\begin{tabular}{|c|c|c|c|c|c|c|}
\hline Léxico & Tot. Estados & Estados & Transiçбes & Tempo & Min. & $\begin{array}{c}\text { Autômato } \\
\text { compactado }\end{array}$ \\
\hline LEX1.full & 985.437 & $53.783(5 \%)$ & $82.218(9 \%)$ & $1: 09$ & 10 & $266 \mathrm{~Kb}$ \\
\hline LEX1.dir & 522.098 & $33.206(6 \%)$ & $49.891(10 \%)$ & $0: 39$ & 6 & $133 \mathrm{~Kb}$ \\
\hline LEX1.rev & 491.898 & $42.918(9 \%)$ & $59.493(12 \%)$ & $0: 37$ & 5 & $156 \mathrm{~Kb}$ \\
\hline LEX10.full & 8.271 .497 & $176.557(2 \%)$ & $391.416(5 \%)$ & $10: 36$ & 83 & $993 \mathrm{~Kb}$ \\
\hline LEX10.dir & 4.388 .763 & $105.967(2 \%)$ & $220.224(6 \%)$ & $4: 48$ & 44 & $556 \mathrm{~Kb}$ \\
\hline LEX10.rev & 3.955 .594 & $114.297(3 \%)$ & $224.164(5 \%)$ & $4: 25$ & 40 & $552 \mathrm{~Kb}$ \\
\hline
\end{tabular}

Comparando os resultados de LEX $\$$.full e LEX*.dir com LEX*.w, podemos observar melhor o impacto dos atributos nas entradas no léxico (Tabela 14).

Tabela 14 - Compação de LEX*.dir e LEX*.full com LEX*.w

\begin{tabular}{|c|c|c|c|c|}
\cline { 2 - 5 } \multicolumn{1}{c|}{} & LEX1.dir & LEX10.dir & LEX1.full & LEX10.full \\
\hline Número de estados & $+40 \%$ & $+41 \%$ & $+126 \%$ & $+134 \%$ \\
\hline Número de transiçōes & $+25 \%$ & $+22 \%$ & $+106 \%$ & $+117 \%$ \\
\hline Tamanho do autômato & $+32 \%$ & $+21 \%$ & $+163 \%$ & $+116 \%$ \\
\hline
\end{tabular}

Analisando LEX*.dir (entradas diretas, pela palavra), vê-se que as informações sobre os atributos causaram um aumento de pouco mais de $20 \%$ no tamanho do autômato final, enquanto que o autômato que inclui também as entradas reversas (LEX*.full) teve um aumento de mais de $100 \%$ em seu tamanho. Assim, dependendo da aplicação, um melhor formato para as entradas reversas pode ser estudado, caso isso represente um problema.

\subsection{Comparações e Análise dos Resultados}

Nesse capítulo será feita uma comparação entre os resultados obtidos com esse trabalho e com resultados obtidos por outros pesquisadores. Para referência, serão utilizados os trabalhos de Mehryar Mohri (AT\&T) [MOH95] e de Kowaltowski, Lucchesi e Stolfi (Unicamp) [KOW98]. 
A Figura 16 mostra os resultados obtidos por Mohri, usando o pacote FSM (introduzido na seção 3.4.4). Trabalhando com léxicos completos (palavras + atributos) de várias línguas, e fazendo a conversão do formato original para um formato mais apropriado, o sistema foi capaz de tratar léxicos de grande porte $(+800.000$ entradas, $+27 \mathrm{Mb})$, mas com tempos às vezes muito altos ( +18 horas, em um CrayII com $128 \mathrm{Mb}$ de memória).

\begin{tabular}{|c|c|c|c|c|c|c|}
\hline DICTIONARIES & Name & $\begin{array}{l}\text { FDELAF } \\
\text { French V.7 }\end{array}$ & $\begin{array}{l}\text { FDELACF } \\
\text { Compound }\end{array}$ & $\begin{array}{c}\text { GDELAF } \\
\text { General }\end{array}$ & $\begin{array}{c}\text { EDELAF } \\
\text { English }\end{array}$ & $\begin{array}{c}\text { IDELAF } \\
\text { Italian }\end{array}$ \\
\hline & $\mathrm{Nb}$ of lines & 672,000 & 156,000 & 828,000 & 145,000 & 612,000 \\
\hline & Initial size & $21.2 \mathrm{Mb}$ & $5.6 \mathrm{Mb}$ & $27.9 \mathrm{Mb}$ & $3.6 \mathrm{Mb}$ & $20 \mathrm{Mb}$ \\
\hline \multirow[t]{7}{*}{ AUTOMATA } & $\mathrm{Nb}$ of states & 84,600 & 322,800 & 389,650 & 48,770 & 78,320 \\
\hline & $\overline{\mathrm{Nb}}$ of transitions & 181,910 & 466,570 & 633,520 & 101,970 & 177,350 \\
\hline & Size & $2.4 \mathrm{Mb}$ & $7.6 \mathrm{Mb}$ & $10 \mathrm{Mb}$ & $1.2 \mathrm{Mb}$ & $2.3 \mathrm{Mb}$ \\
\hline & Compacted size & $818 \mathrm{~Kb}$ & $1.88 \mathrm{Mb}$ & $2.70 \mathrm{Mb}$ & $447 \mathrm{~Kb}$ & $806 \overline{\mathrm{Kb}}$ \\
\hline & Nb of codes & 13,200 & 1,750 & 14,950 & 1,590 & 11,190 \\
\hline & Size of codes & $358 \mathrm{~Kb}$ & $445 \mathrm{~Kb}$ & $403 \mathrm{~Kb}$ & $25 \mathrm{~Kb}$ & $257 \mathrm{~Kb}$ \\
\hline & Total firal size & $1.2 \mathrm{Mb}$ & $1.9 \mathrm{Mb}$ & $3.1 \mathrm{Mb}$ & $470 \mathrm{~Kb}$ & $1.1 \overline{\mathrm{Mb}}$ \\
\hline \multirow[t]{4}{*}{ TIME SPENT } & Constr. (CRAY) & - & $12 \mathrm{~h} 40$ & $18 \mathrm{~h} 53$ & - & - \\
\hline & Constr. (HP) & $12^{3} 30$ & - & - & $4^{2} 55^{2}$ & $12^{3} 30$ \\
\hline & Constr. (NEXT) & Ih18' & - & - & $17^{\prime}$ & $1120^{3}$ \\
\hline & 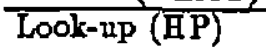 & 90 w/ms & $90 \mathrm{w} / \mathrm{ms}$ & $90 \mathrm{w} / \mathrm{ms}$ & $90 \mathrm{w} / \mathrm{ms}$ & $90 \mathrm{w} / \mathrm{ms}$ \\
\hline
\end{tabular}

Figura 16 - Resultados obtidos por Mohri com o FSM Library [MOH95]

Comparativamente, o sistema proposto nesse trabalho foi capaz de tratar léxicos de mais de 8.000 .000 de entradas ( $11 \mathrm{Mb}$ ) em pouco mais de 10 minutos e necessitando de apenas $32 \mathrm{Mb}$ de memória, gerando uma representação final compactada de menos de $1 \mathrm{Mb}$, como visto na seção 6.3. Entretanto, como os léxicos usados por Mohri apresentavam muitos mais atributos associados, como pode ser notado pela relação entre o tamanho e o número de linhas dos arquivos, uma comparação detalhada dos resultados não pode ser estabelecida.

Um outro trabalho muito importante na área é o de Kowaltowski, Lucchesi e Stolfi (referenciados nesse trabalho de forma resumida por KLS, cujo trabalho está resumido na seção 4.1), cujos resultados podem ser comparados diretamente com os obtidos nesse trabalho devido a utilizarem o mesmo léxico como base para testes (no caso, o léxico do NILC).

Em [KOW98], eles converteram um léxico de 1.490 .002 palavras distintas (com seus respectivos atributos), das quais foram geradas 4.500 .688 entradas para criar o dicionário. Como 
resultado, obtiveram um autômato com 190.795 estados e 346.534 transições, representados em um arquivo único arquivo de apenas $1089 \mathrm{~Kb}$.

O trabalho de KLS, decorrente de muitos anos de pesquisa na área, é realmente excepcional em seu segmento: trabalha com uma representação final altamente otimizada; usa uma heurística especial em uma fase de pós-minimização; e cria um formato de representação eficiente para cada léxico.

No trabalho aqui apresentado não foi utilizado o léxico completo do NILC nos testes, devido à limitações físicas de memória. Entretanto, trabalhando com $10 \%$ do total, os resultados ficaram equivalentes aos resultados obtidos por KLS no tratamento de $100 \%$ do léxico! Uma grande diferença se deve ao formato de representação dos atributos (principalmente das entradas reversas), que sem dúvida ainda permitem otimizações. 


\section{Conclusões}

Esse capítulo apresenta as conclusões e contribuições desse trabalho, assim como a relação dos possíveis trabalhos futuros.

\subsection{Conclusões}

Autômatos finitos se apresentam como excelentes dispositivos para representação de grandes léxicos de língua natural. Aliado ao uso de bons algoritmos e estruturas de dados, podese implementar um sistema extremamente eficiente, capaz de converter léxicos de milhões de palavras e trabalhar com autômatos de dezenas de milhões de estados. Dependendo do tamanho do problema, um micro doméstico (PC, 64Mb memória) pode ser suficiente. Já para problemas maiores (autômatos com mais de 15 milhões de estados, por exemplo), uma workstaion com mais memória se faz necessária.

Os atributos lexicais podem ser codificados eficientemente em um léxico de forma a permitir a melhor taxa possível de otimização pelo sistema de codificação, desde que se leve em consideração as características básicas de re-aproveitamento de estados no autômato. Assim, o tamanho final do autômato compactado incluindo os atributos pode ficar apenas $20 \%$ maior (ou até menos) que o autômato equivalente sem os atributos.

\subsection{Resumo das contribuições}

Como contribuição principal foi proposto um sistema de codificação eficiente de léxicos em autômatos, incluindo todas as estruturas de dados e algoritmos, além da implementação de um protótipo $100 \%$ funcional do sistema ${ }^{20}$. Também foi sugerido um formato otimizado de representação dos atributos léxicos do léxico do NILC, incluindo a descrição BNF completa desse formato.

\footnotetext{
${ }^{20}$ Quanto à disponibilidade do protótipo, consultar o site do NILC (http://nilc.icmc.sc.usp.br), ou diretamente o autor por correio eletrônico em mcouto@null.net.
} 
O sistema proposto nesse trabalho irá possibilitar, juntamente com a base lexical que está sendo organizada no NILC, que o grupo disponha de um ambiente de geração de dicionários específicos para determinadas aplicações, além de funções e bibliotecas de acesso aos mesmos. Isso irá representar uma importante ferramenta para o grupo que trabalha com pesquisa e desenvolvimento de aplicações em PLN.

\subsection{Trabalhos futuros}

Um trabalho importante a ser desenvolvido é a melhoria no formato proposto de representação dos atributos do léxico do NILC, de forma a se obter uma representação ainda mais compacta, e também mais detalhada do léxico original (já que alguns dos atributos originais, tais como regra de derivação e regência, por exemplo, foram descartados).

Outro trabalho importante seria um módulo de gerenciamento de memória próprio, para permitir que o sistema possa tratar problemas ainda maiores, mesmo em workstations de médio poder computacional. Esse módulo seria muito importante também para quaisquer outros sistemas que necessitem de grandes quantidade de memória RAM para trabalhar.

Um futuro trabalho muito interessante poderia ser a remodelagem do sistema, de forma a se utilizar dois processos concorrentes (ou pseudo-concorrentes) comunicando-se por memória compartilhada: um processo responsável pela inserção de palavras e outro pela minimização do autômato. Uma abordagem poderia ser a utilização de threads, ou até mesmo o uso de bibliotecas de comunicação como PVM e MPI.

Por fim, mas não menos importante, poderia ser criada uma interface gráfica de acesso ao sistema proposto nesse trabalho, inclusi ve com possibilidade de visualização gráfica do autômato gerado por partes ou por completo (nesse último caso apenas para pequenos autômatos). 


\section{Referências Bibliográficas}

[AHO74] Aho, A.V.; J.E. Hopcroft; Ullman, J.D. The Design ana Analysis of Computer Algorithms. Addison-Wesley, 1974.

[AHO86] Aho, A.V.; Sethi, R.; Ulman, J.D. Compilers: Principles, Techniques and Tools. Addison-Wesley, 1986.

[APP88] Appel, A.W.; Jacobson, G. J. The World's Fastest Scrabble Program. Communications of ACM, 31(5), 572-578, 585, 1988.

[BRZ62] Brzozowski, J.A. Canonical Regular Expressions and Minimal State Graphs for Definite Events. Mathematical Theory of Automata, MRI Symposia Series, v. 12 (Polytechnic Press, Polytechnic Institute of Brooklyn, NY, 1962), p. 529-561.

[CPM97] Combinatorial Pattern Matching '97. Lecture Notes in Computer Science, vol. 1264, 1997.

[GRI73] Gries, D. Describing an Algorithm by Hopcroft. Acta Inf. 2, 97-109, 1973.

[GRO89] Gross, M.; Perrin, D. Eletronic Dictionaries and Automata in Computations Linguistics. Lecture Notes in Computer Science, vol. 377, 1989.

[HOP79] Hopcorft, J.E.; Ullman, J.D. Introduction to Automata Theory, Languages and Computation. Addison-Wesley, 1979.

[HOP71] Hopcroft, J.E. An $n \log n$ Algorithm for Minimizing the States in a Finite Automaton. The Theory of Machines and Computations (Academic Press, NY, 1971), p. 189-189.

[KOW93] Kowaltowski, T.; Lucchesi, C.L Applications of Finite Automata Representing Large Vocabularies. Software-Pratice and Experience, 23(1), 15-20, 1993.

[KOW95a] Kowaltowski, T.; Lucchesi, C.L.; Stolfi, J. Minimization of Binary Automata. Journal of the Brazilian Computing Society, 3(1), 36-42, 1995.

[KOW95b] Kowaltowski, T.; Lucchesi, C.L.; Stolfi, J. Application of Finite Automata in Debugging Natural Language Vocabularies. Journal of the Brazilian Computing Society, 3(1), 5-11, 1995.

[KOW98] Kowaltowski, T.; Lucchesi, C.L.; Stolfi, J. Finite Automata and Efficient Lexicon Implementation. Relatório Técnico IC-92-2, DCC/UNICAMP, 1998.

[LAN96] Langsam, Y.; Augenstein, M.J.; Tenenbaum, A.M. Data Structs Using $C$ and $C++$. Prentice Hall, 2a. ed., 1996.

[MOH95] Mohri, M. On Some Applications of Finite-State Automata Teory to Natural Language Processing. Natural Language Engineering 1, Cambridge University Press, 1995. 
[NO097] Van Noord, G. FSA Utilities: A Toolbox to Manipulate Finite-State Automata, Lecture Notes in Computer Science, vol. 1260, 1997, p.87-108.

[NUN96] Nunes, M.G.V. et al. A Construção de um Léxico para a Língua Portuguesa: Lições Aprendidas e Perspectivas. II Workshop de Processamento Computacional do Português Escrito e Falado, Curitiba, PR, 61-70, Outubro de 1996.

[PAC96] Pacheco, H.C.F. Uma Ferramenta de Auxilio à Redação. Dissertação de Mestrado, DCC-UFMG, 24 de outubro de 1996.

[RAY93] Raymond, D.R.; Wood, D. Grail papers. Departament of Computer Science, University of Waterloo, Canada. Internet: ftp://cs-archive.uwarterloo.edu

[REV92] Revuz, D. Minimization of Acyclic Deterministic Automata in Linear Time. Theoretical Computer Science, 92(1), 181-189, 1992.

[WAT93a] Watson, B.W. A Taxonomy of Finite Automata Minimization Algorithms. Internet: http://www.ribbitsoft.com/research/watson

[WAT93b] Watson, B.W. A Taxonomy of Finite Automata Construction Algorithms. Internet: http://www.ribbitsoft.com/research/watson

[WAT96] Watson, B.W. FIRE Lite: FAs and REs in C++. Lecture Notes in Computer Science, vol. 1260, 1997, p.167-188.

[WIA96] Workshop on Implementing Automata '96. Lecture Notes in Computer Science, vol. $1260,1997$.

[WOO87] Wood, D. Theory of Computation. Harper \& Row, NY, 1987. 


\section{Apêndice A - B.N.F. do Léxico do NILC}

15. = primeira pessoa do singular

25. = segunda pessoa do singular

35. = terceira pessoa do singular

1P. = primeira pessoa do plural

2P. = segunda pessoa do plural

3P. = tercelra pessoa do plural

3SP. = 3a pessoa do sing. e 3a pessoa do plural

A. = aumentativo

ABREV. = abreviatura

ADT. = aditiva

ADJ. = adjetivo

ADVE, = adversativa

AFIR. = afirmação

ALTER. = alternativa

ART. $=$ artigo

AUX. $=$ auxiliar

BI. = bitransitivo

C. $=$ contração

CAR. = cardina

CAUS. = causa!

CIR-LUG. = circunstância lugar

CIR-TEMP. = circunstância tempo

CIR-MOD. = circunstância modo

COMP. = comparativa

CONC. = concessiva

CONCL. = conclusiva

COND. = condicional

CONFOR = conformativa

CONJ. = conjunção

CONS. $=$ consecutiva

COORD. = coordenativa

D. = diminutivo

DE. = definido

DEM. = demonstrativo

DUV. = dúvida

ENC. = ênclise

EXPL. = explicativa

F. $=$ feminino

FIN. = final

FRA. = fracionário

FRA-ORD. = fracionário e ordinal

FUT-PRES. $=$ futuro do presente

FUT-PRET. = futuro do pretérito

FUT-SUBJ. = futuro do subjuntivo

GERUN. = gerúndio

$\mathbf{I}=$ artigo indefinido

IMP-AFIRM. = imperativo afirmativo

INDE. = pronome indefinido

INF-PESS. $=$ infinitivo pessoal
INT. = intransitivo

INTE. = intensidade

INTEG. = integrante

INTER. = interrogativo

INT-CAUS. = interrogativo de causa

INT-LUG. = interrogativo de lugar

INT-MOD. = interrogativo de modo

INT-TEMP. = interrogativo de tempo

INV. = invariável

LIG. = ligação

$\mathbf{M}_{\mathbf{1}}=$ masculino

MESOC. $=$ mesóclise

MUL. = multiplicativo

$\mathbf{N}_{\mathbf{1}}=$ nulo

NEG. = negação

NOM. = nome próprio

NUM , = numeral

OBL-AT. = pessoal obliquo átono

OBL-TO. = pessoal oblíquo tônico

ORD. = ordinal

PARTIC. $=$ participio

PL. = plural

POSS. $=$ possessivo

PREF. $=$ prefixo

PREP. = preposição

PRES. = presente

PRES-SUBJ. = presente do subjuntivo

PRET-IMPERF. $=$ pretérito imperfeito

PRET-IMPERF-SUBJ. = pret. imperfeito do subj.

PRET-M-Q-P. = pretérito mais que perfeito

PRET-PERF. = pretérito perfeito

PRON. = pronome

PRONOM. =pronominal

PROPOR. = proporcional

RET. = pessoal reto

REL. = relativo

REFL. = reflexivo

S. = substantivo

SI. $=$ singular

SIGL. = sigla

SU. = superlativo

SUBORD. = subordinativa

TD. = transtivo direto

TEMP. = temporal

$\mathbf{T I}$ = transtivo indireto

TRAT. = tratamento

$V_{.}=$verbo

2G. = dois gênero

2N. = dois número 
:: = Significa "é definido como".

I Significa "ou".

$\{$ \} Significa que o conteúdo pode ser repetido nenhuma ou várias vezes.

< > Significa que o conteúdo é uma construção sintática BNF.

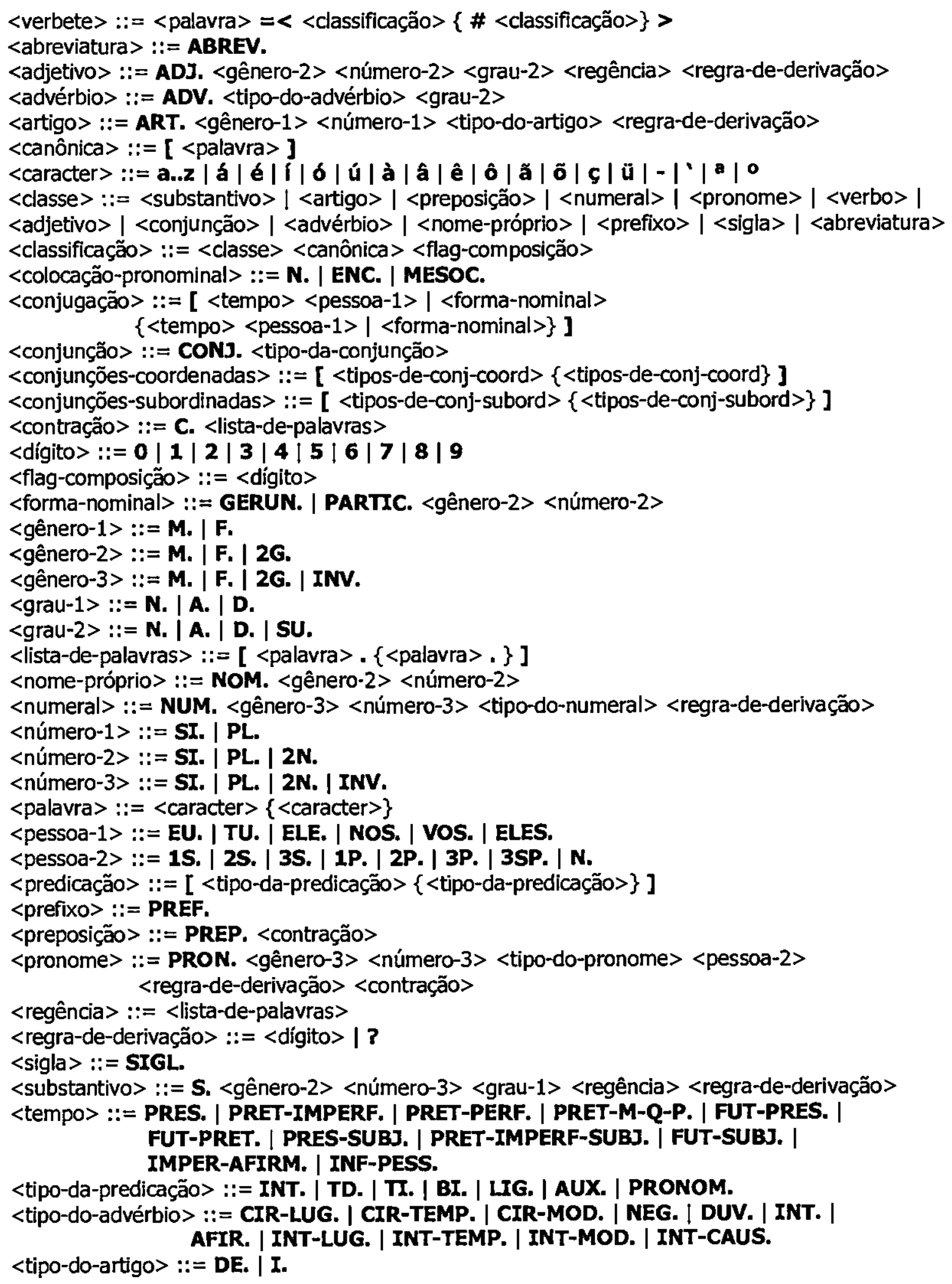


<tipo-da-conjunção> ::= [ COORD. <conjunções-coordenadas> |

SUBORD. <conjunções-subordinadas>

\{ COORD. <conjunções-coordenadas> 1

SUBORD. <conjunções-subordinadas > \} ]

$<$ tipo-do-numeral> ::= ORD. | MUL. | FRA. | FRA-ORD. | CAR.

<tipo-do-pronome> ::= TRAT. | RET. | OBL-AT. | OBL-TO. | POSS. | DEM. | INDE. | INTE. | REL. | REFL.

<tipos-de-conj-coord> ::= ADIT. | ADVE. | ALTER. | CONCL. | EXPL.

$<$ tipos-de-conj-subord $>::=$ INTE. | CAUS. | COMP. | CONC. | COND. | CONS. | FIN. TEMP. | PROPOR. | CONFOR.

<verbo> ::= V. <predicação> <conjugação> <colocação-pronominal> <regência > 